\title{
The evolution of seabed stiffness during cyclic movement in a riser touchdown zone on
} soft clay

\author{
F. Yuan, D.J. White \& C. D. O’Loughlin
}

\section{Feng Yuan}

$\mathrm{PhD}$

Zhejiang University

866 Yuhangtang Road, Hangzhou, China

Tel: +86 13735474967

Email: yuanfen5742@163.com

\section{David J. White}

Shell EMI Professor of Offshore Engineering

Centre for Offshore Foundation Systems, The University of Western Australia 35 Stirling Highway, Crawley, WA6009, Australia

Tel: +61864883086

Fax: +61864881044

Email: david.white@uwa.edu.au

\section{Conleth O'Loughlin}

Associate Professor

Centre for Offshore Foundation Systems, The University of Western Australia 35 Stirling Highway, Crawley, WA6009, Australia

Tel: +61864887326

Fax: +61 864881044

Email: conleth.oloughlin@uwa.edu.au 
The evolution of seabed stiffness during cyclic movement in a riser touchdown zone on

soft clay

\author{
F. Yuan, D.J. White \& C. D. O’Loughlin
}

Keywords: Offshore engineering, Pipeline, Riser, Soil stiffness, Clay

\begin{abstract}
Steel catenary risers are pipelines that convey fluids from the seabed to floating structures. The stiffness of the pipe-seabed response, which is the ratio between soil resistance and pipe embedment, in the touchdown zone strongly affects the fatigue accumulation rate, so is an important design parameter. This paper reports a centrifuge modelling study into the longterm pipe-seabed interaction forces on soft clay seabeds, with tests representing many months of behaviour at prototype scale. The results show that the penetration and extraction resistance during large amplitude cycles degrades during the initial few tens of cycles, in the same way that cyclic penetrometer tests capture the fall in soil strength from the intact to the remoulded state. Calculations using bearing capacity factors for a cylinder provide good predictions of this response, although if the cycles of movement involve the pipe breaking away from the soil then the resistance reduces by more than the ratio of intact to remoulded strength, and this is attributed to entrainment of water in the soil around the pipe. However, with further cycles, as pore pressure dissipation occurs, the seabed stiffness recovers due to the gain in soil strength from consolidation. Eventually, the remoulding and water entrainment effects are wholly erased, and the stiffness exceeds the initial state. These observations suggest that current design practice - which factors down the soil stiffness to represent the influence of the cyclic degradation and remoulding process - may overlook a significant effect that raises the seabed stiffness, and potentially also reduces the fatigue life.
\end{abstract}




\section{INTRODUCTION}

Offshore risers are pipes used to transport oil and gas from the seabed to a floating vessel. Catenary risers are simply an extension of a seabed pipeline which lifts away from the seabed and hangs as a catenary in the water column (Fig 1a). To assess the stability and fatigue of a catenary riser it is necessary to predict the seabed bathymetry and resistance forces through the touchdown zone (TDZ).

A catenary riser undergoes cyclic motions both in-plane and out-of-plane due to loads imposed by the floating structure and from waves and currents acting in the water column. Continuous small-amplitude cycles are always present from the ambient sea state, and larger motions occur during storms.

These motions are resisted primarily by vertical and lateral forces in the riser touchdown zone. In deep water, where catenary risers are used, the soil is generally soft clay (Randolph, 2004). The strength of the clay varies as the soil is disturbed by the riser and remoulded. In addition, scour of the soil can lead to the development of a large trench surrounding the riser pipe, which alters the geometry of the riser through the TDZ (Palmer, 2000; Theti and Moros, 2001; Bridge and Howells, 2007).

A fatigue concentration occurs around the TDZ, which is influenced by the bathymetry of the seabed through the TDZ as well as the stiffness (or the non-linear load-displacement response) as the riser moves vertically (Langner, 2003; Clukey et al., 2007; Randolph et al., 2013; Shiri, 2014).

This paper is focussed on the changing strength of the seabed, and the evolution of a seabed trench, around an element of riser pipe undergoing vertical and combined vertical-horizontal motions on a soft clay. Previous studies have established rigorous theoretical solutions for the vertical and vertical-horizontal penetration resistance of a pipe into undrained clay using 
plasticity limit analysis and numerical finite element modelling (Aubeny et al., 2005; Randolph and White, 2008; Martin and White, 2012). Other studies have extended these theoretical solutions for plastic penetration to model the full non-linear penetration and extraction response, including hysteretic effects (Aubeny and Biscontin, 2009; Randolph and Quiggen, 2009) (Figure 1a). A limited range of experimental studies have been used to validate these models, through short term cyclic loading (Bridge et al., 2004; Aubeny et al., 2008). Recent work has focussed on calibrating the reduction in stiffness caused by remoulding in the first few tens of movement cycles (Aubeny et al., 2015). In addition, threedimensional simulations of a catenary riser touchdown zone have been performed at various scales, yielding bending moment profiles through the TDZ (Bridge and Willis, 2002; Hodder and Byrne, 2010; Elliot et al., 2014; Wang et al., 2014)

Current prediction models for riser-seabed interaction do not explicitly incorporate the strength properties of the seabed soil to quantify the resistance to cyclic motion of the riser. Instead, they define an initial penetration resistance curve linked to the intact strength, and a level of degradation of the resistance is selected for cyclic motions, but not from the remoulding properties of the soil.

The seabed strength can also rise following disturbance. This is due to reconsolidation as the remoulding-induced excess pore pressures dissipate. This effect has been previously quantified via cyclic T-bar penetrometer tests (White and Hodder, 2010) and small-amplitude vertical cyclic riser tests (Hodder et al. 2009). Estimates of the timescale required for pore pressure dissipation around a shallowly-embedded pipe can be made using the solutions given by Krost et al. (2011) and Chatterjee et al. (2013).

A second effect that is not included in current riser-seabed interaction models is the influence of out-of-plane motions. These motions are not directly relevant to fatigue, since the fatigue life is usually controlled by the top and bottom fibres of the riser pipe, which are loaded 
through in-plane motions. However, out-of-plane motions may affect the in-plane vertical riser-seabed stiffness, through the interaction of the vertical and horizontal seabed loading (Martin and White, 2012). Current steel catenary riser (SCR) touchdown models are based on analyses and experiments involving purely vertical loading and movement, although some experiments have studied large lateral movements into trench walls (Oliphant et al., 2009).

To advance the understanding of catenary riser touchdown modelling, the specific aims of this experimental study are:

1. To quantify the relative influences of remoulding and reconsolidation on the cyclic vertical riser-seabed response, for realistic long-term durations of loading.

2. To quantify the effect of small amplitude out-of-plane movements on the cyclic vertical riser-seabed response.

Figure 1(b) shows the notation for the present study.

\section{MODEL SEABED PROPERTIES}

The model seabed used in the experiment was kaolin clay, normally consolidated from slurry in the UWA beam centrifuge at an acceleration of 50g. A piezoball penetrometer with a diameter of $15 \mathrm{~mm}$ at model scale (750 $\mathrm{mm}$ at prototype) was used to measure the intact and remoulded soil strength (Figure 2a). The undrained soil strength was back-calculated based on the net resistance, q, and a bearing factor of 10.5 (Martin and Randolph, 2006). The intact soil strength, $\mathrm{s}_{\mathrm{u}}$, increased linearly with depth at a rate of $0.9 \mathrm{kPa} / \mathrm{m}$ (in prototype depth units) over the depth range of interest, with negligible intercept at the mudline. Rapid undrained cycles were performed with the piezoball fully embedded in the soil to determine the profile of remoulded strength, $s_{u, \text { rem }}$, which is fitted by a gradient of $0.32 \mathrm{kPa} / \mathrm{m}$, corresponding to a sensitivity of $S_{t}=s_{u} / s_{u, \text { rem }}=2.5$ (Figure 2(b)).

A consolidation coefficient of $c_{v}=2.6 \mathrm{~m}^{2} /$ year, based on previous testing (Acosta-Martinez et 
al. 2012), has been used throughout the interpretation of this test programme in the analysis of

consolidation. Based on post-test water content measurements, the mean effective unit weight over the depth of interest (to $\sim 3 \mathrm{~m}$ depth) was $6 \mathrm{kN} / \mathrm{m}^{3}$.

\section{MODEL PIPE}

During each test a rigid model pipeline was cyclically penetrated into the model seabed. The pipeline was $20 \mathrm{~mm}$ in diameter and $120 \mathrm{~mm}$ long at model scale, or $1 \mathrm{~m}$ in diameter at prototype scale. The length to diameter ratio of 6 is sufficient to neglect end effects (Chung et al. 2006).

Figure 3(a) shows the model pipe assembly and the attached vertical load cell. Due to the low soil strength, accurate measurement of the pipe-seabed resistance is of great importance. Although the vertical load cell is zeroed at the exact original mudline before each test, additional corrections are still needed to identify the different components of resistance. The measured vertical load $(F)$ includes soil buoyancy $\left(F_{\mathrm{bs}}\right)$, water buoyancy $\left(F_{\mathrm{bw}}\right)$ and the force caused by the change in the radial position of the pipe assembly within the centrifuge acceleration field $\left(F_{r}\right)$ :

$F=F_{s}+F_{\mathrm{bs}}+F_{\mathrm{bw}}+F_{r}$

where the soil resistance $\left(F_{s}\right)$ and the soil buoyancy $\left(F_{\mathrm{bs}}\right)$ together constitute the geotechnical resistance $\left(F_{g}\right)$ :

$F_{g}=F_{s}+F_{\text {bs }}$

The buoyancy force from the soil and water depend on the pipe elevation relative to the mudline, which itself changes in elevation (Figure 3(b)). For sections of the pipe assembly that are above the mudline $\left(V_{\text {sub }}\right)$, water buoyancy causes upward resistance; for sections below the mudline $\left(V_{\mathrm{emb}}\right)$, there is additional soil buoyancy. The relative elevation of the pipe 
assembly and the mudline determine the submerged volume $\left(V_{\text {sub }}\right)$ and embedded area $\left(V_{\text {emb }}\right)$.

Figure 4(a) shows the sizes of all sections of the assembly, including the loadcell, connector, shaft and pipe, where $D$ and $L$ are respectively the pipe diameter and length. The individual components of resistance are defined as follows:

\section{(1) Soil buoyancy force $F_{\mathrm{bs}}$}

The soil buoyancy force is the submerged weight of the displaced soil, which is the product of the effective unit weight $\left(\gamma^{\prime}\right)$ and the volume of the embedded segment $\left(V_{\mathrm{emb}}\right): F_{\mathrm{bs}}=\gamma^{\prime} V_{\mathrm{emb}}$. The profile of effective unit weight with depth was established from moisture content measurements determined from core samples taken in undisturbed regions of the sample after testing.

(2) Water buoyancy $F_{\text {bw }}$

The water buoyancy force is the product of the water unit weight $\gamma_{w}$ and the volume of both the submerged and embedded sections: $F_{b w}=\gamma_{w}\left(V_{\mathrm{sub}}+V_{\mathrm{emb}}\right)$. As the load cell is zeroed at the original mudline, only the change in submerged volume is required, which is determined by the vertical displacement relative to the mudline.

\section{(3) Effect of spinning radius $F_{r}$}

With vertical displacement of the pipe assembly, there is a change in the radial position in the acceleration field, which changes the $g$ level and the simulated self-weight. If $r_{1}$ is the effective radius (giving the required 50g), as the pipe moves from $r_{1}$ to $r_{2}$, the change of $g$ level is $\omega^{2}\left(r_{2}-r_{1}\right)$ (Figure $\left.4 \mathrm{~b}\right) . F_{r}$ can be calculated by the product of the mass of the segments below the load cell and the change of $g$ level.

The $F_{r}$ and $F_{\mathrm{bw}}$ components have been subtracted from the measured loads to separate out the geotechnical resistance, which is the resistance applicable to the field situation. 


\section{TEST PROGRAMME}

A set of nine tests composed of three groups was performed. The groups involved different types of vertical cycling:

- Group 1: Cycles between lower and upper displacement limits with the upper limit above the original mudline ('surface-breaking' tests).

- Group 2: Cycles between lower and upper displacement limits, with the pipe remaining embedded within the soil ('embedded' tests).

- Group 3: Cycles between a specified downward load (setting the lower displacement limit of each cycle) and an upper displacement limit above the mudline ('loadcontrolled' tests).

Within each group, three tests were performed. The first test involved zero lateral movement whilst the other two tests involved different levels of horizontal cyclic displacement in a sinusoidal pattern superimposed on the vertical movement. The lateral movement were relatively small in amplitude (up to $+/-0.1 D$ ) and increased the displacement path length by up to $4.25 \%$. The key parameters and test identifiers are summarised in Table 1 .

The displacement inputs to the Group 1 and Group 2 tests are shown in Figure 5. The two groups reached the same maximum embedment, but the displacement range was only $1.5 \mathrm{D}$ in Group 2 meaning that the pipe remained embedded at the upper limit, preventing free water from becoming entrained in the seabed soil. In contrast, water entrainment could occur in each cycle during the Group 1 tests as the pipe entered and exited the soil.

During the Group 3 tests the upper limit of the cycles was fixed at a specified displacement of $1 D$ above mudline, but the lower limit was defined by a load limit of $F / D L=10 \mathrm{kPa}$. The use of a load limit allows the process of two-dimensional trench evolution to be modelled, with the displacement reached in each cycle being controlled by the changing soil strength and 
trench depth. The Group 3 test variations used the same superimposed pattern of horizontal sinusoidal movements.

In all tests the vertical pipe velocity was set at $2.5 \mathrm{~mm} / \mathrm{s}$ (model scale), or $0.125 \mathrm{D} / \mathrm{s}$.

\section{RESULTS: FIRST PENETRATION AND REMOULDING BEHAVIOUR}

\section{Fixed-amplitude tests (Group 1 and Group 2)}

The vertical geotechnical resistance $\left(F_{g}\right)$ in selected cycles is shown in Figure 6 (Group 1) and Figure 7 (Group 2). These results are compared with theoretical predictions and the effects of horizontal movement, water entrainment and trench evolution are highlighted in the discussion.

The soil resistance, $F_{s}$, has been calculated from the intact and remoulded strength profiles and the bearing factors given by Tho et al. (2012), which vary with depth depending on the strength ratio, $s_{u} / \gamma D$. For this soft normally-consolidated strength profile a deep bearing factor of 10.5 is reached within $\sim 1.5$ diameters of penetration. The soil buoyancy, $F_{\mathrm{bs}}$, has been calculated based on Archimedes' principle, as outlined by Equation 2 and the subsequent discussion.

The theoretical calculation using the intact strength shows good agreement with the initial purely vertical penetration. The vertical resistance concurrent with horizontal movement is over-estimated typically by $10 \%$, indicating the slight influence of combined verticalhorizontal loading, for the superimposed small-amplitude cycles.

The theoretical calculation using the remoulded strength profile indicates the significant influence of soil buoyancy. This component of resistance is equivalent to a bearing pressure of $F / D L \sim 5 \mathrm{kPa}$ when the pipe is fully embedded. The calculated profiles of penetration and extraction resistance are offset downwards to replicate the observed trench development, as 
indicated by the depth at which penetration resistance is first registered.

Compressive (upwards) soil resistance is measured during most of the upwards pipe movement in the $200^{\text {th }}$ cycle. This indicates that the soil buoyancy exceeds the resistance caused by the soil strength. Calculations using the remoulded strength profile give slightly higher penetration and extraction resistance compared to the measurements after 50 and 200 cycles. This indicates that a greater reduction in soil strength occurs around the oscillating pipe, compared to the cycling of the fully-embedded ball penetrometer (Figure 2(b)), and this can be attributed to water entrainment in tests of Group 1.

In contrast, for the embedded tests that do not allow water entrainment, the penetration and extraction resistance after 50 and 200 cycles is predicted well using the remoulded soil strength, coupled with the soil buoyancy term (Figure 7). As for the surface-breaking tests, the small amplitude horizontal cycles cause a slight reduction in vertical penetration resistance.

The cyclic evolution of penetration resistance at a depth of $z / D=2$ is shown in Figure 8 in normalised form as $F_{\mathrm{s}} / F_{\mathrm{s} 0}$ where $\mathrm{F}_{\mathrm{s} 0}$ is the soil strength resistance during the initial penetration. For all tests there is an initially rapid reduction in resistance, matching the cyclic ball penetrometer test, to $F_{s} / F_{\mathrm{s} 0} \sim 0.4$ (i.e. $1 / S_{t}$ ). For the embedded tests the resistance then remains constant, but for the surface-breaking tests there is a slower continuous fall in resistance due to water entrainment and the deepening of the trench (reducing the effective depth of soil at $z / D=2$ ).

In summary, conventional bearing capacity theory gives good predictions of the initial penetration resistance, which is to be expected given that the strength profile has been derived using a penetrometer that creates a flow-round failure mechanism similar to the pipe. In addition, the penetration and extraction resistance after a short period of cycling can be accurately predicted using the remoulded strength from a cyclic penetrometer test, for cycles 
of riser movement that do not break the soil surface. For surface-breaking cycles the

resistance is further reduced by water entrainment. In all cases the soil buoyancy force is the significant component of the vertical resistance.

\section{Load-controlled tests (Group 3)}

The results from key cycles during the early phase of the load-controlled tests are shown in Figure 9. In these tests the vertical limit of each cycle is set by the load limit of $F / D L=10$ $\mathrm{kPa}$ (which corresponds to $F_{g} \sim 8 \mathrm{kPa}$ ). The reduction in soil strength due to remoulding leads to a progressive increase in the embedment reached during each cycle. Over the first 100 cycles, soil softening is evident and the penetration and extraction resistance of the $100^{\text {th }}$ cycle is symmetric about the soil buoyancy profile. As for the Group 1 tests, the remoulded strength leads to a slight over-prediction of the resistance, reflecting the additional influence of water entrainment.

The lateral cycles cause a slight increase in the rate of embedment with cycles, with tests L24H2 and L24H4 (involving lateral cycles) reaching a depth of $z / D=1.5$ by cycle 100 whilst test L24 (no lateral cycles) reaches only $z / D=1.3$ by cycle 100 .

\section{RESULTS: RECONSOLIDATION}

\section{Reconsolidation mechanism}

The load-controlled tests continued for a greater period of time than the displacementcontrolled tests, and identified a further important feature of soil behaviour. The seabed resistance increased during the later cycles causing the depth at which the vertical load limit was reached to reduce, as shown for cycle $N=1000$ compared to $N=100$ in Figure 9.

This behaviour reflects reconsolidation of the soil due to dissipation of the excess pore pressure created by the remoulding process. The principal cause of the strength reduction during cyclic remoulding around a pipe or penetrometer (in the absence of water entrainment) 
is the generation of positive excess pore pressure. This is only a transient effect, and after the

pore pressure has dissipated the soil is densified and thus has a higher undrained strength.

This behaviour can be captured by simple critical state models, as illustrated by White and Hodder (2010) for cyclic T-bar tests with intervening periods of consolidation.

\section{Changes in moisture content}

The increase in density caused by reconsolidation was identified from moisture content measurements taken in the test footprints after the full test program was completed (Figure 10). These measurements were taken from $20 \mathrm{~mm}$ diameter piston samples removed from each footprint. A reduction in moisture content was identified in all of the footprints, although the load-displacement responses indicate that reconsolidation did not occur in the Group 1 and Group 2 footprints until after the tests were complete. The reconsolidation process causes a net reduction in moisture content, even though any water entrainment during the tests creates an increase.

A moisture content profile was also taken remote from the test footprints to identify the initial conditions. These results have been combined with the soil unit weight profile to construct a one-dimensional normal compression line for the in situ soil (in $v-\log \sigma_{v}{ }_{v}$ space), defined by the specific volume (corrected for the swelling that would have occurred when the sample cores were taken at $1 \mathrm{~g}$ ) and the in situ vertical effect stress, $\sigma_{v}^{\prime}=\gamma z$ (Figure 11). The $v-\sigma_{v}^{\prime}$ data points derived from the footprint moisture content profiles over the zone of pipe penetration lie below the NCL, and close to the CSL established for UWA kaolin. This is consistent with a prior stress path involving undrained failure (thus moving to the left from the NCL), followed by reconsolidation along a reload line, leading to contraction.

\section{Effect of reconsolidation on seabed stiffness}


The load-controlled tests were continued for a total of $~ 3000$ cycles, which corresponds to a dimensionless time of $T=c_{v} t / D^{2} \sim 12$. For comparison, the dimensionless period for $90 \%$ dissipation around a pipe resting under constant load at an embedment of $z / D=0.5$ is $T_{90} \sim 2$ (Gourvenec and White, 2010). This corresponds to a period of $\sim 70$ days for a typical SCR in the field (assuming $D=0.5 \mathrm{~m}$, and $c_{v}=2.6 \mathrm{~m}^{2} /$ year, which is reasonable for deepwater clays, as well as being applicable for the present study). The duration of the load-controlled tests is therefore relevant for an SCR in the field, which may remain at the same seabed location for a comparable or greater period of time.

The evolution of the trench depth and the maximum penetration depth (i.e. where $F / D L=10$ $\mathrm{kPa}$ was reached) with cycles and dimensionless time are shown in Figure 12. Separate subplots are used for the early cycles (up to $N=100$ ) and the full test. During the first 100 cycles the penetration depth increases and then stabilises, consistent with the remoulding process observed in the other tests. However, in the subsequent cycles the trench depth continues to increase but the maximum penetration depth reduces. This reflects an increase in the strength of the seabed soil, due to reconsolidation. The reconsolidation - which causes a reduction in moisture content - also drives the increase in trench depth, because the soil contraction causes the seabed surface to settle.

This convergence of the maximum depth and the trench depth causes a sharp rise in the overall seabed stiffness seen by the riser during penetration. The evolution of this penetration stiffness, $K=\left(F_{g_{-} \max } / D L w\right)$, is shown in Figure 13. This stiffness decays for the initial 100 cycles (or until $T \sim 1$ ), with an approximately two-fold reduction that is consistent with the remoulding process. However, the stiffness then rises steadily to reach a plateau of approximately twice the initial penetration stiffness in all three tests. 
This final stiffness is approximately $F_{g} / D L w=25 \mathrm{kPa} / \mathrm{m}$, during cycles with a displacement amplitude of 0.3 diameters. In contrast, the virgin penetration resistance of the seabed was $\sim 10 \mathrm{kPa} / \mathrm{m}$.

The same trend is evident in the unloading stiffness, defined as shown in Figure 14. These results from test L24 show the evolution of the secant unloading stiffness, $K_{\text {sec }}$, during the first $\sim 1 D$ of the uplift stage of key cycles. During the first 100 cycles the unloading stiffness falls, mirroring the secant penetration stiffness and reflecting the remoulding process. The trends shown by this data reflect the short-term model tests results presented by Aubeny et al. (2015), as well as the calculation model they present. However, in later cycles the unloading stiffness rises, reflecting the reconsolidation process. This effect is not considered in current calculation models.

\section{Discussion}

The observed trend of increasing seabed stiffness with time due to consolidation is consistent with previous model tests involving very small-amplitude vertical riser cycles (Hodder et al., 2009). This previous study, also involving centrifuge model test with kaolin clay, observed a significant rise in the small-amplitude riser-seabed stiffness due to consolidation processes following an initial phase of softening due to remoulding.

Overall, it appears that both the small-amplitude stiffness and the overall penetration resistance of soft normally-consolidated seabeds can be significantly affected by reconsolidation processes. These processes occur over a time period that is a small fraction of the period involved in fatigue assessments, so the post-reconsolidation state is likely to govern the fatigue accumulation.

Previous work to calibrate riser TDZ models has focussed on the initial remoulding process, driven by observations in large scale tests involving a few tens of undrained cycles. In 
contrast, the present results, and those of Hodder et al. (2009), achieve more realistic long-

term prototype time scales through the scaling provided by centrifuge model tests. These results show that the stiffness reduction caused by the remoulded process can be entirely erased by reconsolidation effects. Instead, the long term fatigue of SCRs may be controlled by levels of soil stiffness that are higher - thus more onerous - than would be estimated from the intact soil strength, rather than the more tolerable remoulded values that recent research has focused on establishing.

An important future task is to explore the influence on these processes on soil type, and the effect of the slight levels of over-consolidation commonly apparent in the field.

\section{CONCLUSIONS}

The centrifuge model tests performed in this study provide insights associated with long term riser-seabed behaviour that cannot be gained from large scale tests in a practical timescale. The time scaling of centrifuge tests allows the consolidation levels relevant to field-scale fatigue processes to be properly replicated.

Two key conclusions from this work contribute to the understanding of seabed stiffness. Firstly, it is confirmed that bearing capacity theory allows accurate scaling from cyclic penetrometer tests - capturing both intact and remoulded soil strengths - to large-amplitude cyclic riser-seabed interaction forces. The model tests responses over the first few tens of cycles are accurately predicted, although for surface-breaking cycles the water entrainment effect causes a further reduction in the operative soil strength to below the remoulded value. The importance of including soil buoyancy in the analysis is highlighted, and in some cases it is shown that the soil buoyancy force can exceed the resistance from the soil strength.

The second key conclusion is that the dissipation of excess pore pressures created by the disturbance and remoulding of the movement cycles leads to a significant recovery of soil 
strength. In the long term, this consolidation effect can wholly erase the degradation of strength associated with the remoulding and water entrainment processes, causing the seabed stiffness to exceed the initial state. This effect can be captured by simple critical state models for normally-consolidated soil, and mirrors similar observations from other processes involving shearing events interspersed with consolidation periods. These observations suggest that current design practice for the estimation of riser-seabed interaction forces - which discounts the soil stiffness to reflect the remoulding process -overlooks an significant effect that raises the seabed stiffness, and potentially also reduces the fatigue life.

\section{ACKNOWLEDGEMENTS}

The research presented here forms part of the activities of the Centre for Offshore Foundation Systems (COFS), currently supported as a node of the Australian Research Council Centre of Excellence for Geotechnical Science and Engineering (grant CE110001009) and through the Fugro Chair in Geotechnics, the Lloyd's Register Foundation Chair and Centre of Excellence in Offshore Foundations and the Shell EMI Chair in Offshore Engineering (held by the second author). The first author is supported by a particular grant from the National Natural Science Foundation of China (number 51409228), Natural Science Foundation of Zhejiang Province (number LY15E090003) and the Fundamental Research Funds for the Central Universities.

\section{REFERENCES}

Acosta-Martinez, H.E., Gourvenec, S. \& Randolph, M.F. (2012) Centrifuge study of undrained capacity of a skirted foundation under eccentric transient and sustained uplift loading. Géotechnique, 62(4): 317-328. 10.1680/geot.9.P.027. 
Aubeny CP, Shi H, and Murff JD (2005) Collapse loads for a cylinder embedded in a trench in cohesive soil. International Journal of Geomechnics 5(4): 320-325.

Aubeny CP, Gaudin C, and Randolph MF (2008) Cyclic tests of model pipe in kaolin. Proceedings of Offshore Technology Conference, Houston, USA, paper OTC 19494.

Aubeny CP, and Biscontin G (2009) Seafloor-riser interaction model. International Journal of Geomechanics 9(3): 133-141.

Aubeny CP, White TA, Langford T, Meyer V, and Clukey EC (2015) Seabed stiffness model for steel catenary risers. Proceedings of International Symposium On Frontiers in Offshore Geotechnics. Perth, Australia, pp. 351-356.

Bridge C, and Willis N (2002) Steel catenary risers--Results and conclusions from large scale simulations of seafloor interactions. Proceedings of 14th Annual Deep Offshore Technology (DOT) International Conference and Exhibition, New Orleans, USA, pp. 13-15.

Bridge C, Laver K, Clukey E, and Evans T (2004) Steel catenary riser touchdown point vertical interaction model. Offshore Technology Conference, paper OTC 16628.

Bridge C, and Howells H (2007) Steel catenary riser touchdown point vertical interaction models. Offshore Technology Conference, paper OTC 16628.

Chatterjee, S. Gourvenec, S.M \& White D.J. 2014. Assessment of the consolidated breakout response of partially embedded seabed pipelines. Géotechnique 64(5): $391-399$

Chung S.F., Randolph M.F. \& Schneider J.A. (2006) Effect of penetration rate on penetrometer resistance in clay. ASCE Journal of Geotechnical and Geoenvironmental Engineering. 132(9)1188-1196

Clukey EC, Ghosh R, Mokarala P, and Dixon M (2007) Steel catenary riser (SCR) design issues at touch down area. Proceedings of the 17th International Conference on Offshore and Polar Engineering, Lisbon, Portugal, pp. 814-819.

Elliot BJ, Zakeri A, Barrett J, Hawlader B, Li G, and Clukey EC (2013) Centrifuge modelling 
of steel catenary risers at touchdown zone part II: Assessment of centrifuge test results using kaolin clay, Ocean Engineering, 60: 208-218.

Gourvenec SM, and White DJ (2010) Elastic solutions for consolidation around seabed pipelines. Proceedings of Offshore Technology Conference, Houston, UAS, Paper 20554.

Hodder MS, and Byrne BW (2010) 3D experiments investigating the interaction of a model SCR with the seabed. Applied Ocean Research, 32:146-157.

Hodder M, White DJ, and Cassidy MJ (2009) Effect of remolding and reconsolidation on the touchdown stiffness of a steel catenary riser: observations from centrifuge modelling. Proceedings of Offshore Technology Conference, Houston, USA, paper OTC19871.

Krost K., Gourvenec S.M. \& White D.J. (2011). Consolidation around partially-embedded submarine pipelines. Géotechnique, 61(2): 167-173.

Langner CG (2003) Fatigue life improvement of steel catenary risers due to self-trenching at the touchdown point. Proceedings of Annual Offshore Technology Conference, Houston, USA, paper OTC 15104.

Martin CM, and Randolph M (2006) Upper bound analysis of lateral pile capacity in cohesive soil. Gèotechnique, 56(2): 141-145.

Martin CM, and White DJ (2012) Limit analysis of the undrained capacity of offshore pipelines. Géotechnique, 62(9):847-863.

Oliphant J, Maconochie A, White DJ, and Bolton MD (2009). Trench interaction forces during lateral SCR movement in deepwater clays. Proceedings of Offshore Technology Conference, Houston, USA, paper OTC19944.

Palmer A. (2000). Catenary riser interaction with the seabed at the touchdown point. Proceedings of the Deepwater Pipeline and Riser Technology Conference, Houston, USA.

Randolph, MF (2004). Characterisation of soft sediments for offshore applications, Keynote Lecture. Proc. 2nd Int. Conf. on Site Characterisation, Porto, Portugal 1, 209-231. 
Randolph MF, and White DJ (2008) Upper bound yield envelopes for pipelines at shallow embedment in clay. Géotechnique, 58(4):297-301.

Randolph MF, and Quiggin P (2009) Non-linear hysteretic seabed model for catenary pipeline contact. Proceedings of the international conference on ocean, offshore and arctic engineering, ASME, Honolulu, USA, paper OMAE2009-79259.

Randolph MF, Bhat S, Jain S, and Mekha B (2013) Modeling the Touchdown Zone Trench and Its Impact on SCR Fatigue Life. Proceedings of Offshore Technology Conference, Houston, USA, paper OTC 23975.

Shiri H (2014) Response of steel catenary risers on hysteretic non-linear seabed. Applied Ocean Research, 44:20-28

Thethi R, and Moros T (2001) Soil interaction effects on simple catenary riser response. Proceedings of Deepwater Pipeline \& Riser Technology Conference, Houston, USA, pp. 20-29.

Tho KK, Leung CF, Chow YK and Palmer AC (2012) Deep cavity flow mechanism of pipe penetration in clay. Canadian Geotechnical Journal, 49(1): 59-69.

Wang L, Zhang J, Yuan F, Li K (2014) Interaction between catenary riser and soft seabed: Large-scale indoor tests. Applied Ocean Research. 45:10-21.

White DJ and Hodder M (2010) A simple model for the effect on soil strength of remoulding and reconsolidation. Canadian Geotechnical Journal. 47:821-826. 


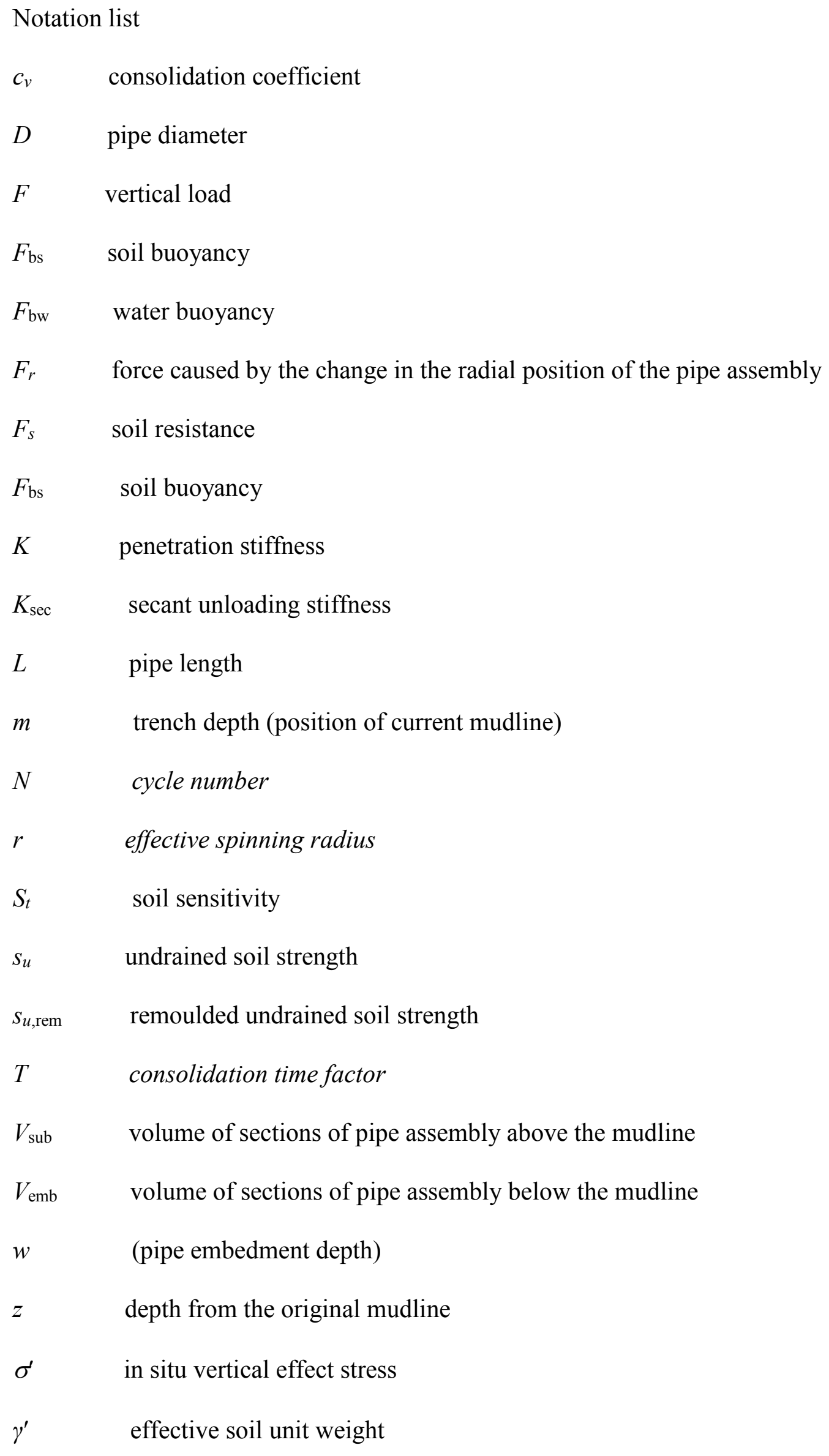


water unit weight

$v$ specific volume

$\omega$ angular velocity 
Table 1. Summary of test parameters

\begin{tabular}{|c|c|c|c|c|}
\hline Group & Test ID & $\begin{array}{l}\text { Upper cyclic } \\
\text { limit }\end{array}$ & $\begin{array}{l}\text { Lower cyclic } \\
\text { limit }\end{array}$ & Horizontal cyclic amplitude \\
\hline \multirow{3}{*}{1} & V80 & \multirow{3}{*}{$w / D=-1$} & \multirow{3}{*}{$w / D=3$} & 0 \\
\hline & $\mathrm{V} 80 \mathrm{H} 2$ & & & $\begin{array}{c}+/-0.05 D(2.42 \% \text { longer } \\
\text { path })\end{array}$ \\
\hline & V80H4 & & & $+/-0.1 D(2.42 \%$ longer path $)$ \\
\hline \multirow{3}{*}{2} & V30 & \multirow{3}{*}{$w / D=1.5$} & \multirow{3}{*}{$w / D=3$} & 0 \\
\hline & $\mathrm{V} 30 \mathrm{H} 2$ & & & $\begin{array}{c}+/-0.05 D(2.42 \% \text { longer } \\
\text { path })\end{array}$ \\
\hline & $\mathrm{V} 30 \mathrm{H} 4$ & & & $+/-0.1 D(4.25 \%$ longer path $)$ \\
\hline \multirow{3}{*}{3} & $\mathrm{~L} 24$ & \multirow{3}{*}{$w / D=-1$} & \multirow{3}{*}{$F / D L=10 \mathrm{kPa}$} & 0 \\
\hline & $\mathrm{L} 24 \mathrm{H} 2$ & & & $\begin{array}{c}+/-0.05 D(2.42 \% \text { longer } \\
\text { path })\end{array}$ \\
\hline & L24H4 & & & $+/-0.1 D(2.42 \%$ longer path $)$ \\
\hline
\end{tabular}




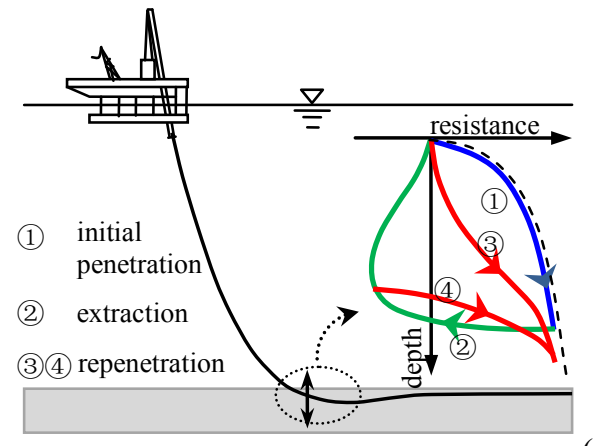

(a)

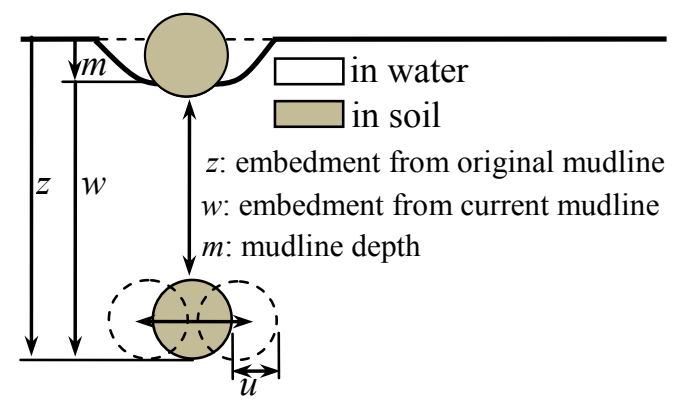

(b) 


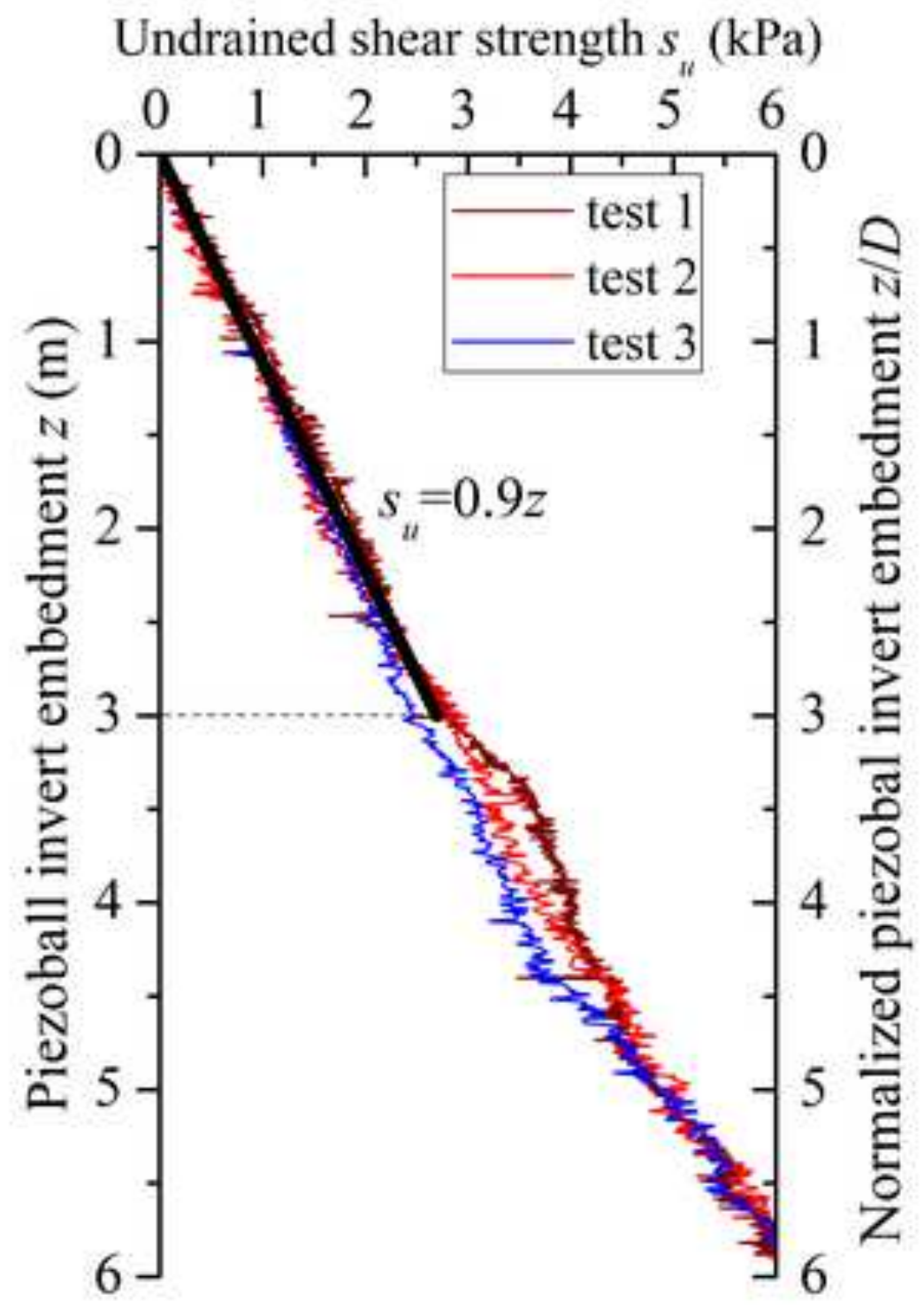




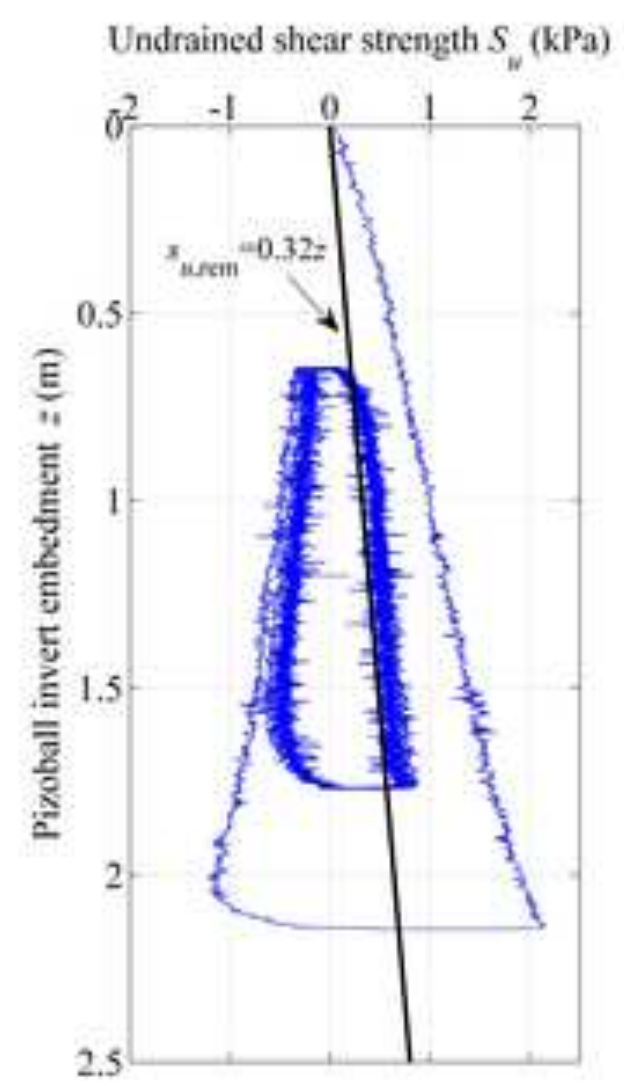




\section{load cell}

\section{connector}

\section{shaft}

pipe

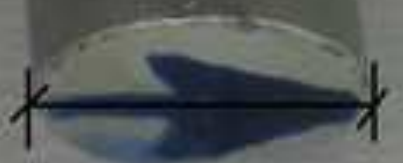

$D=20 \mathrm{~mm}$ 


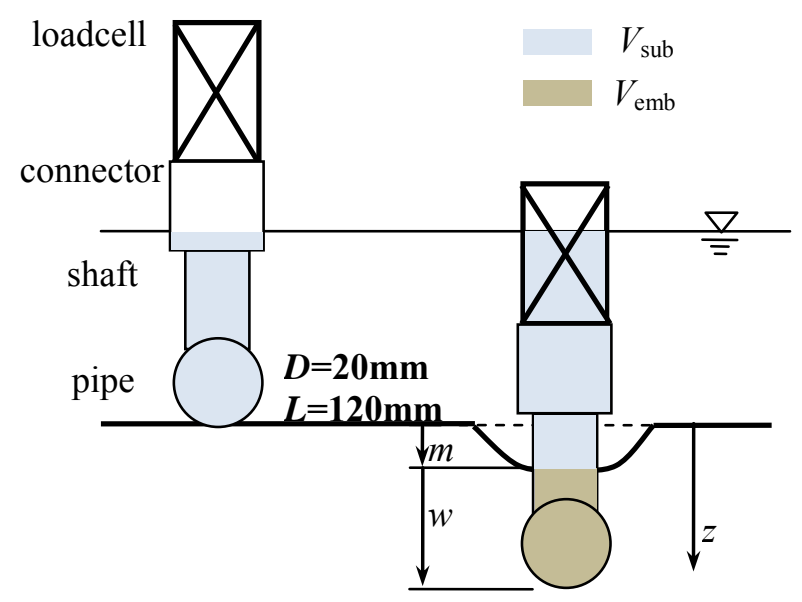




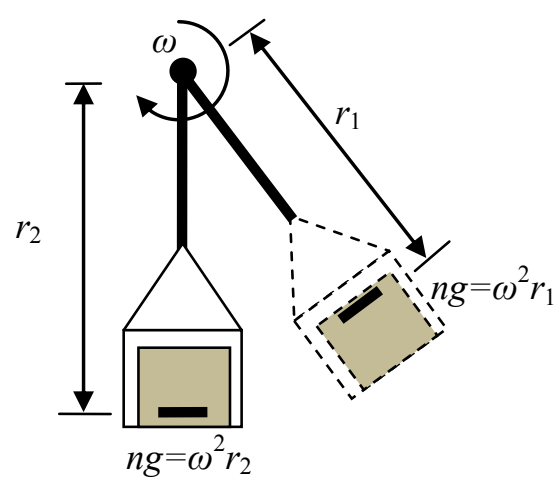




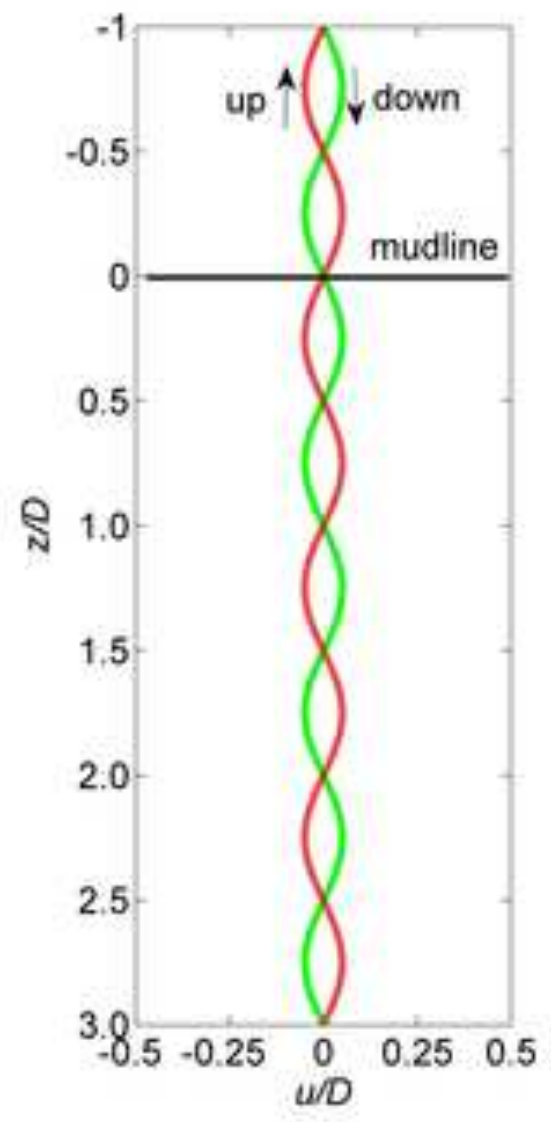




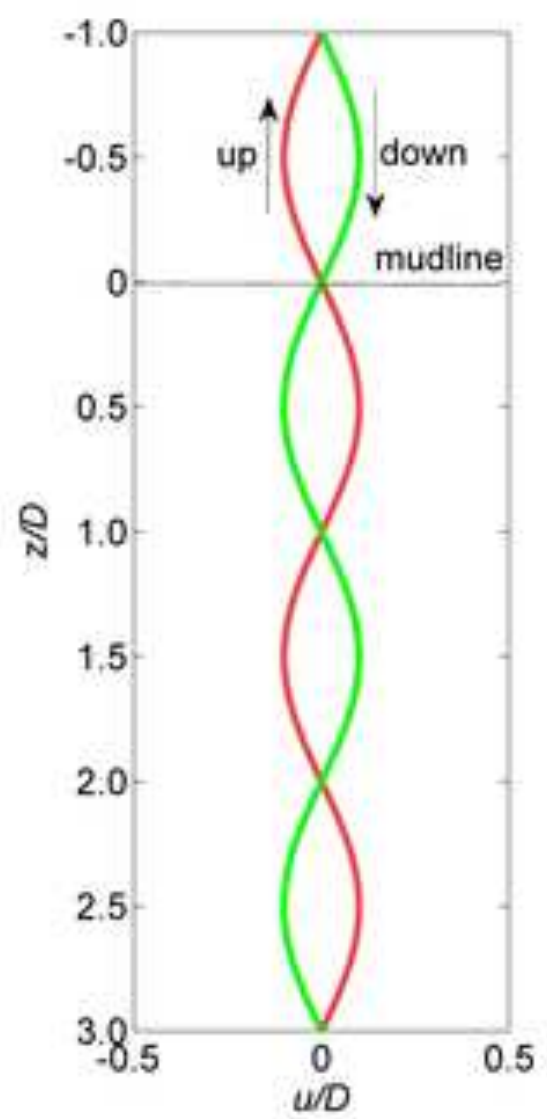




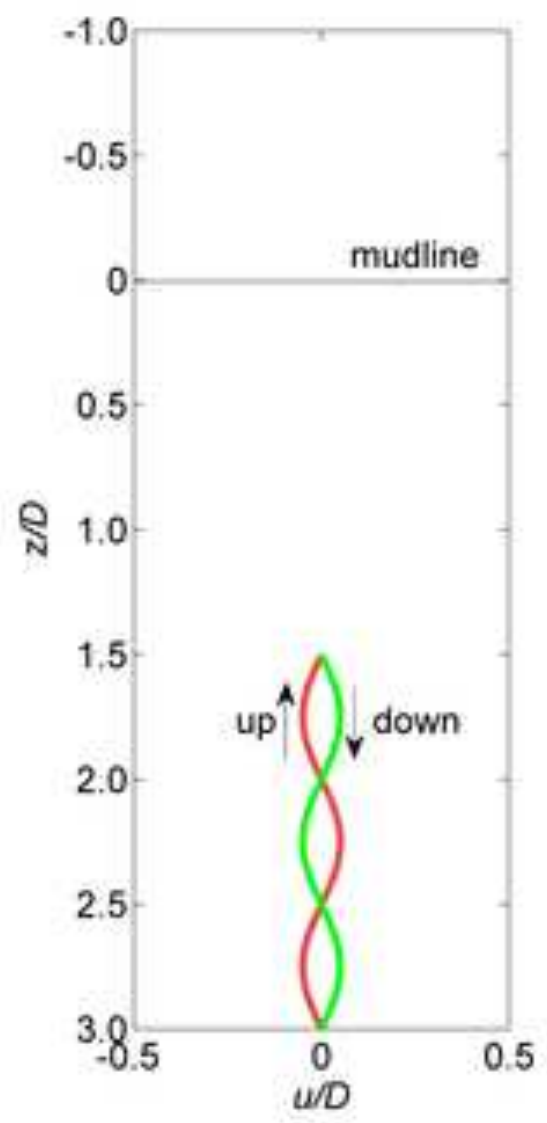




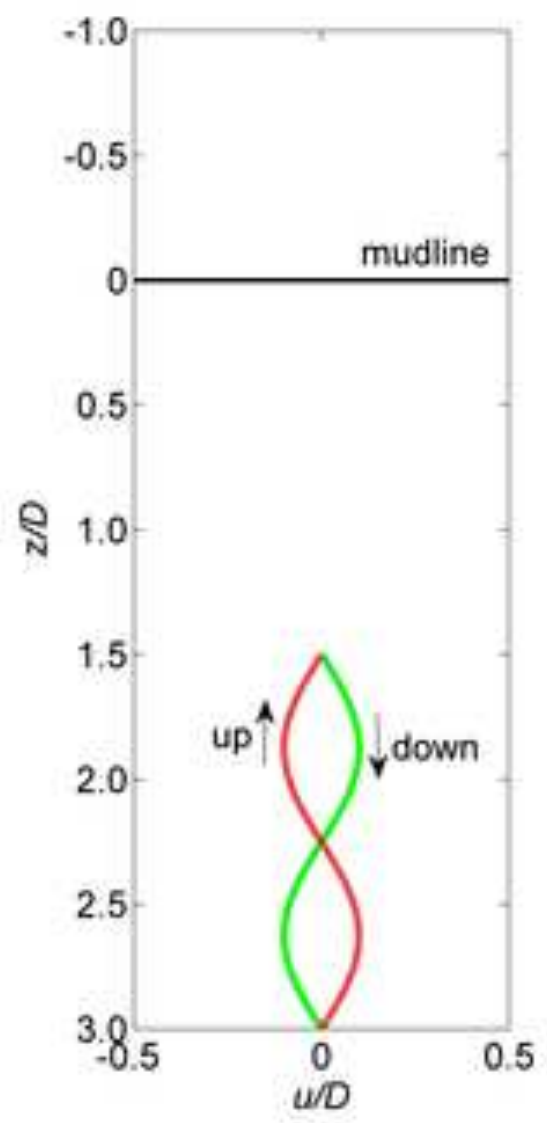




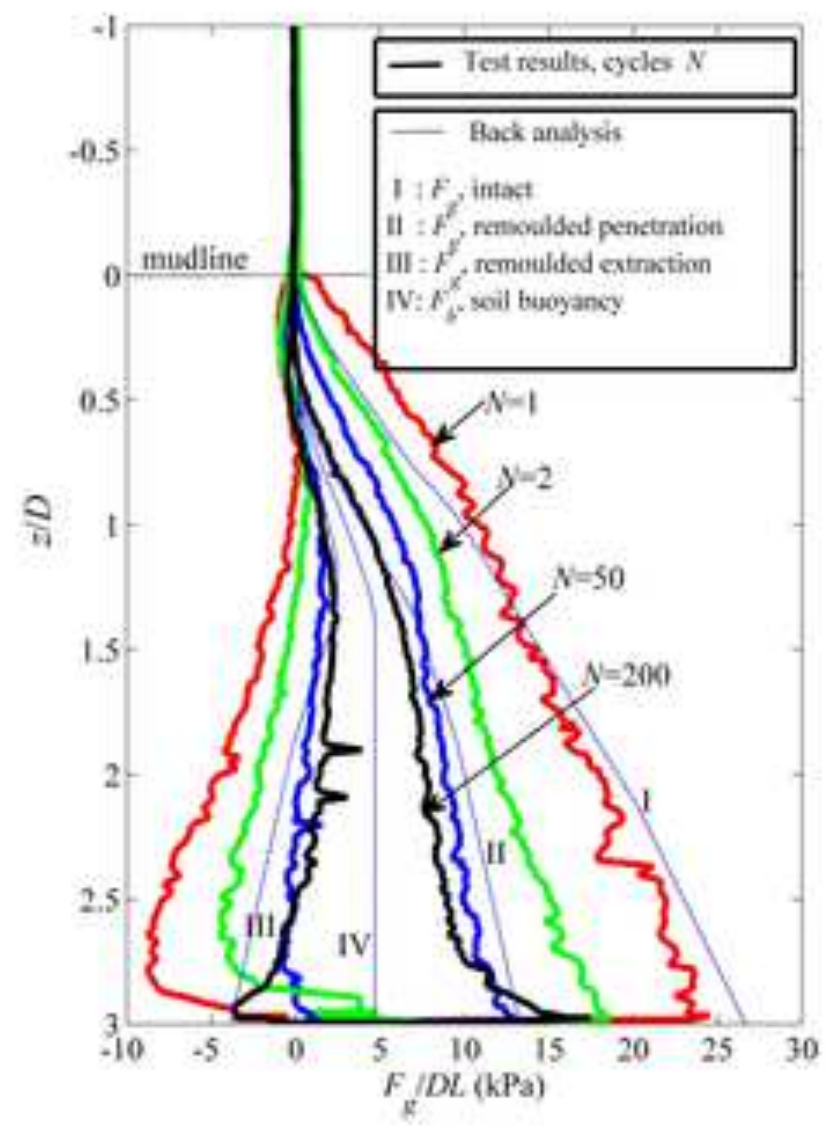




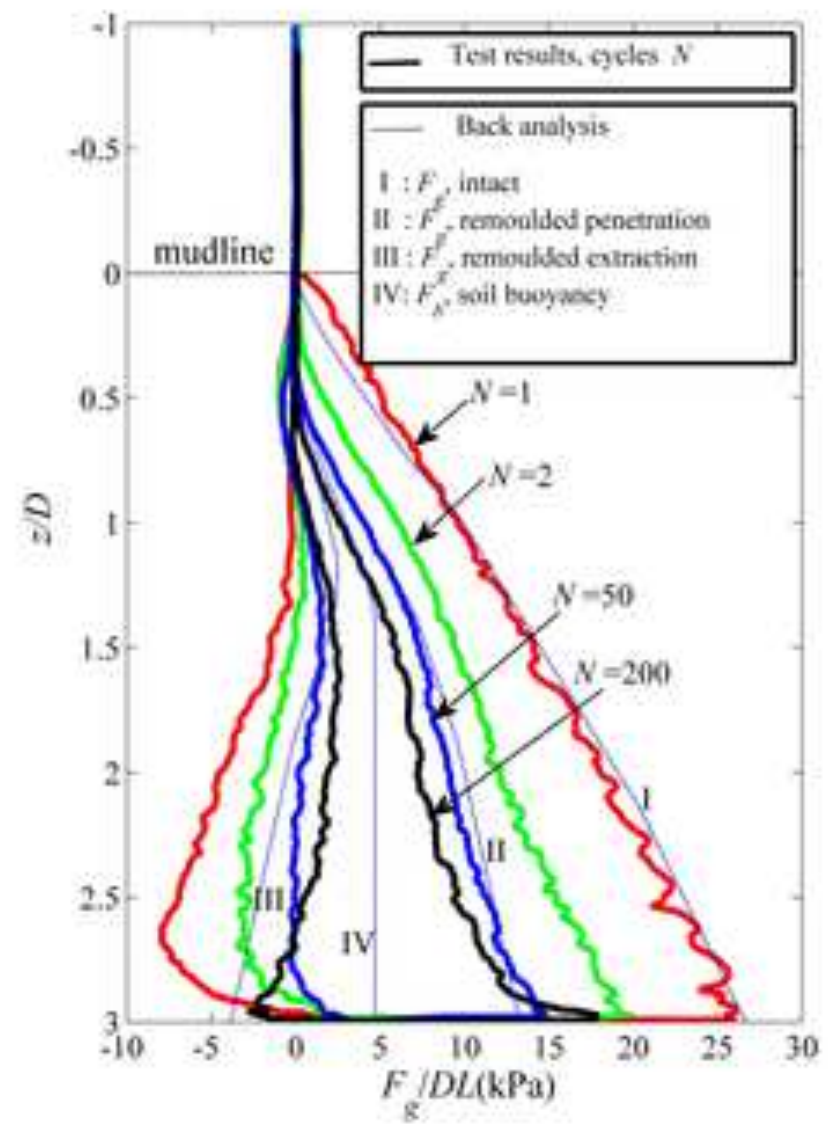




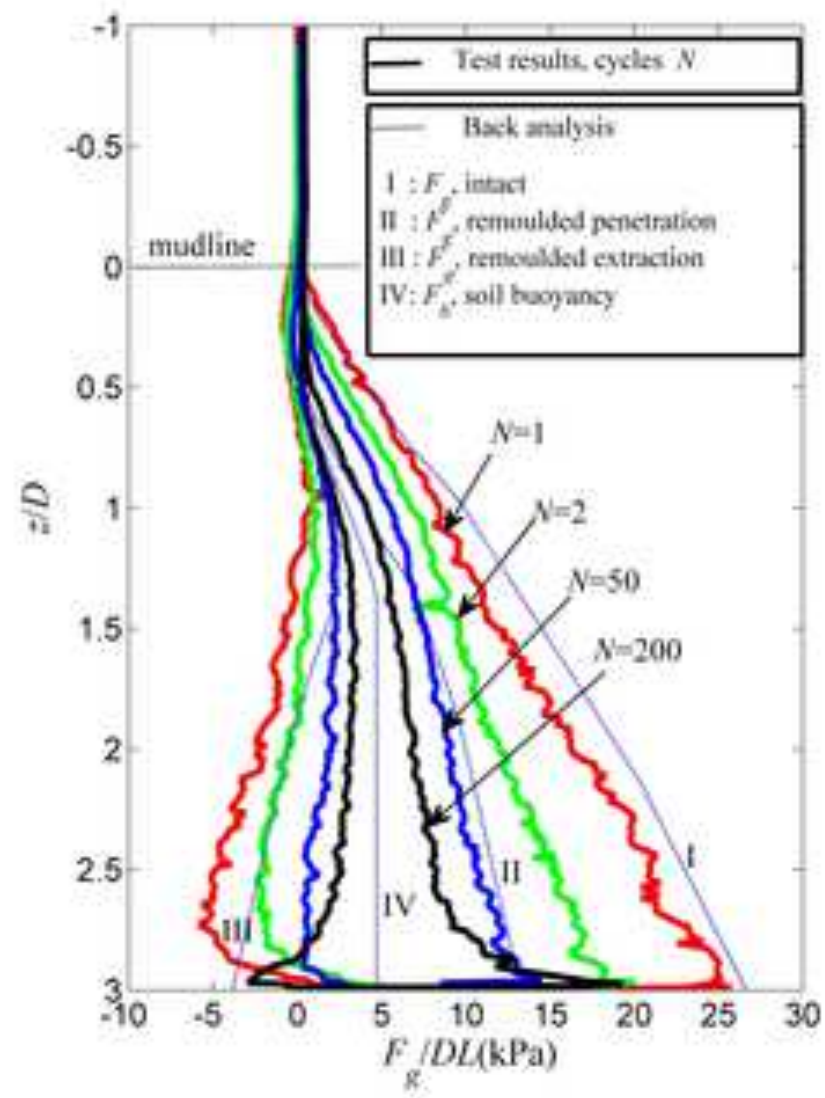




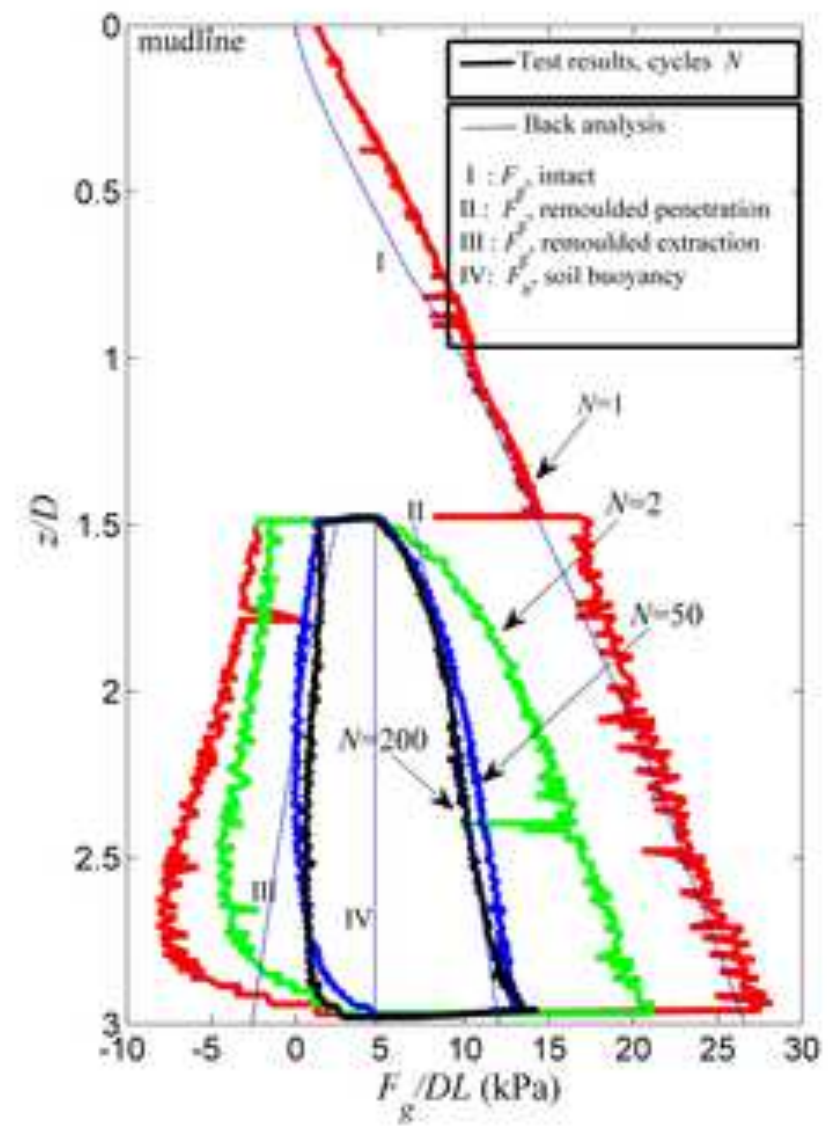




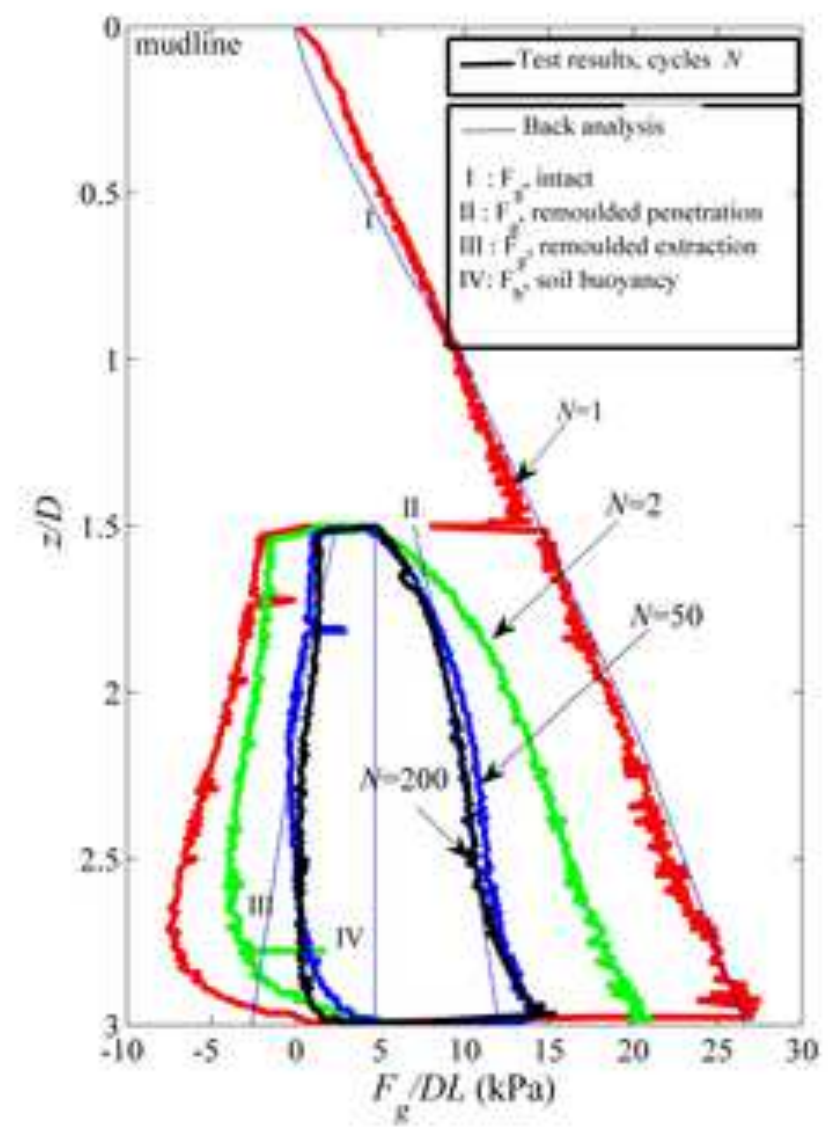




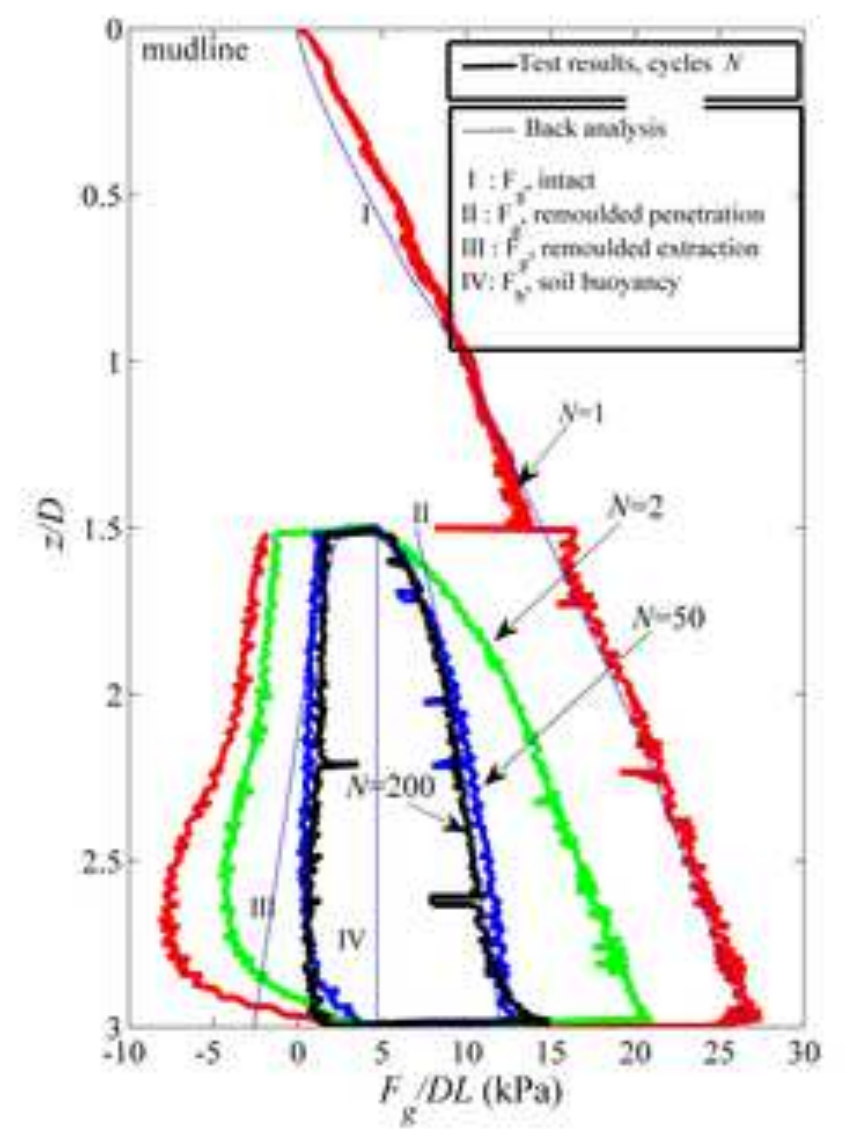




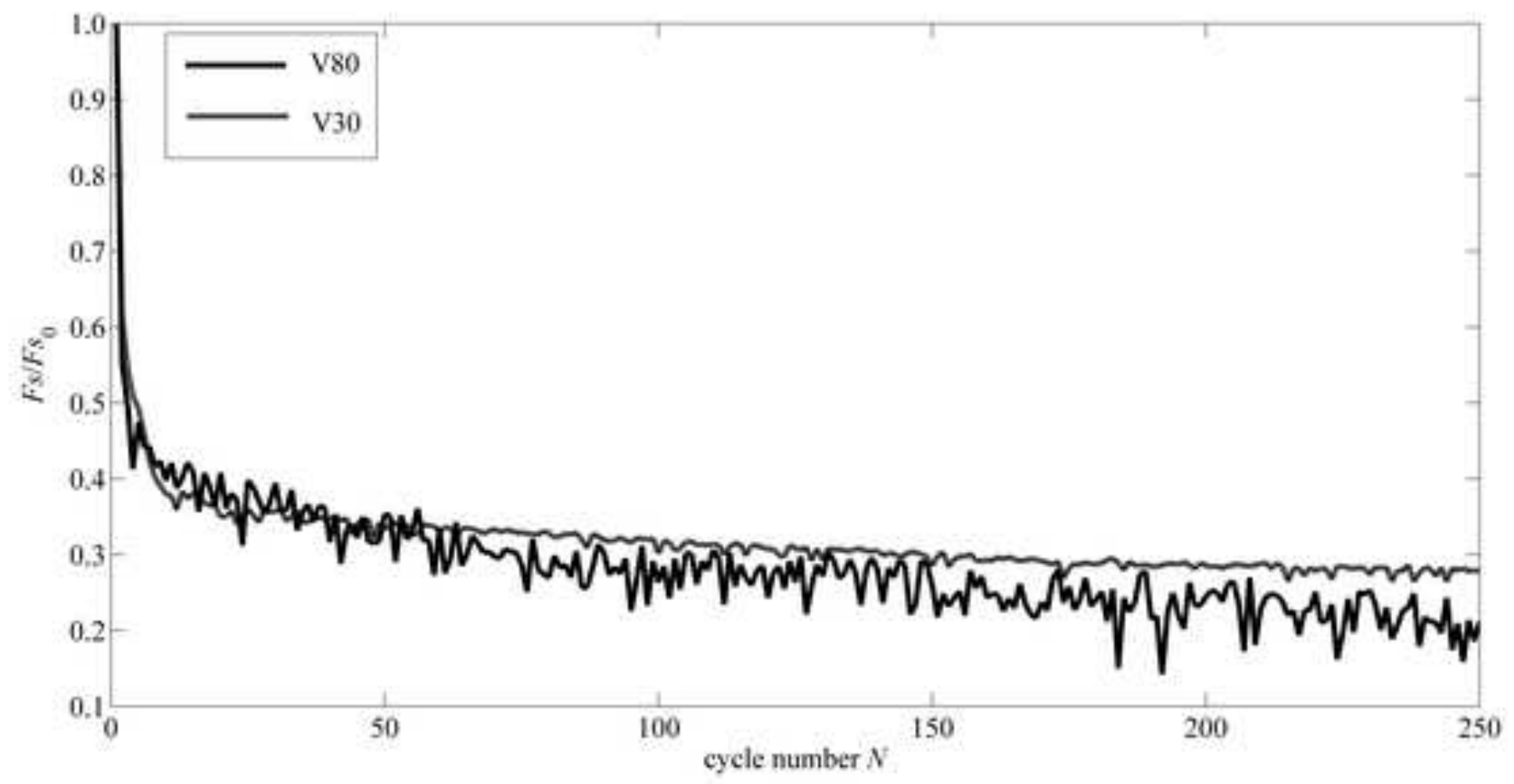




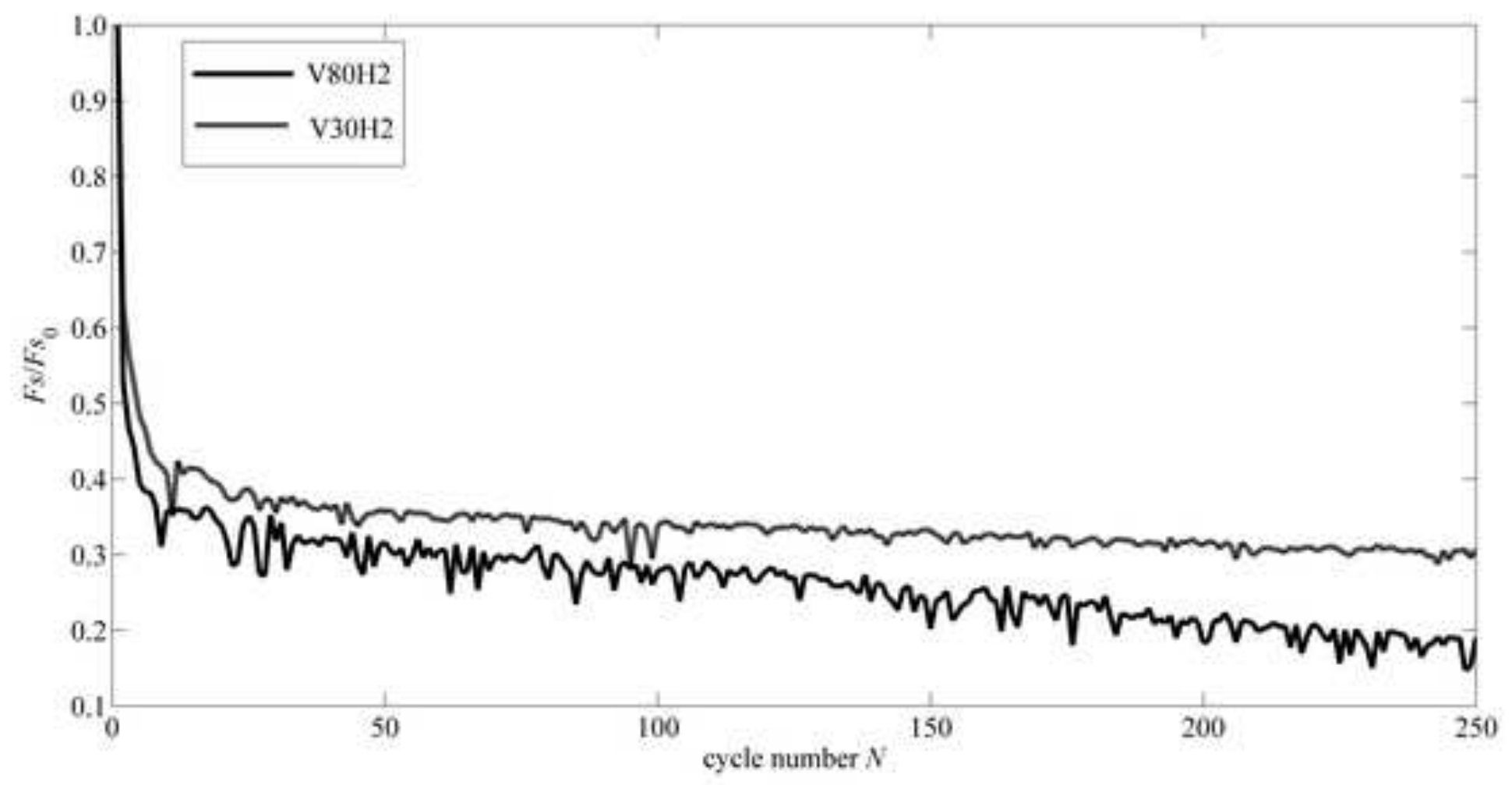




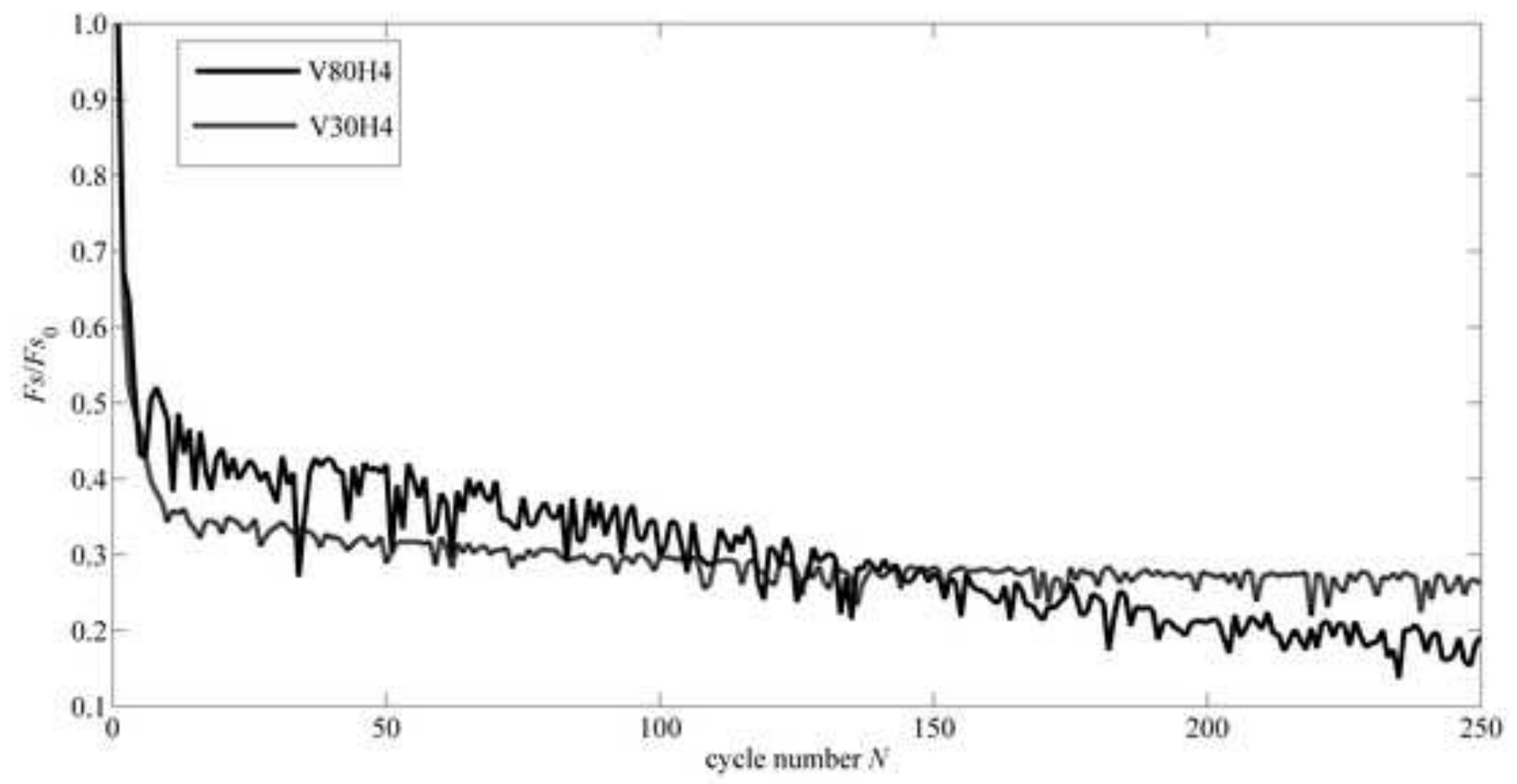




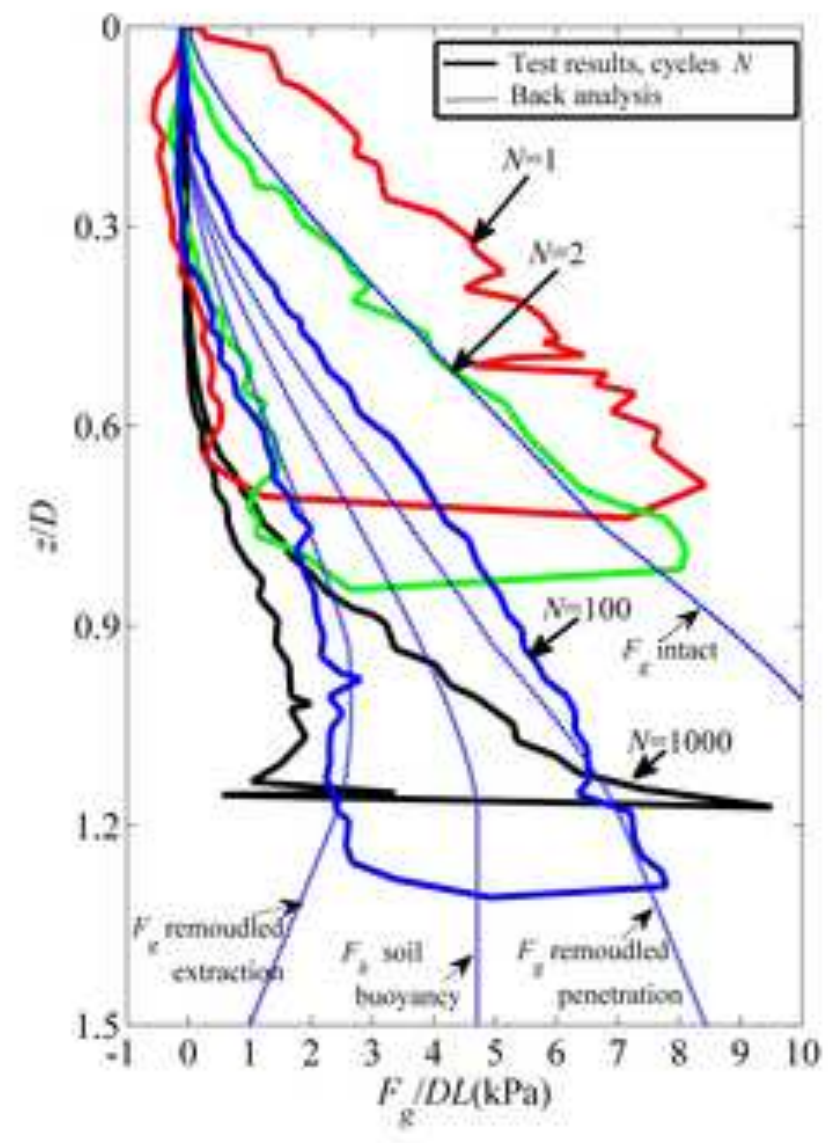




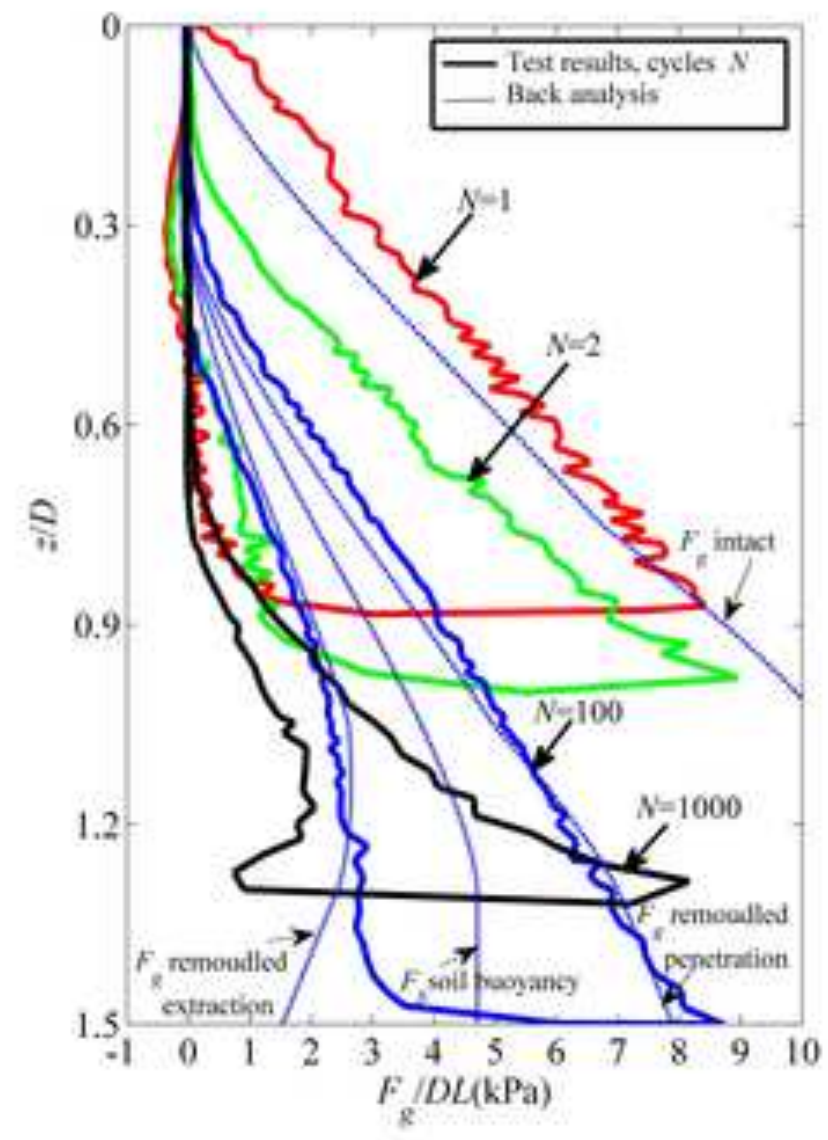




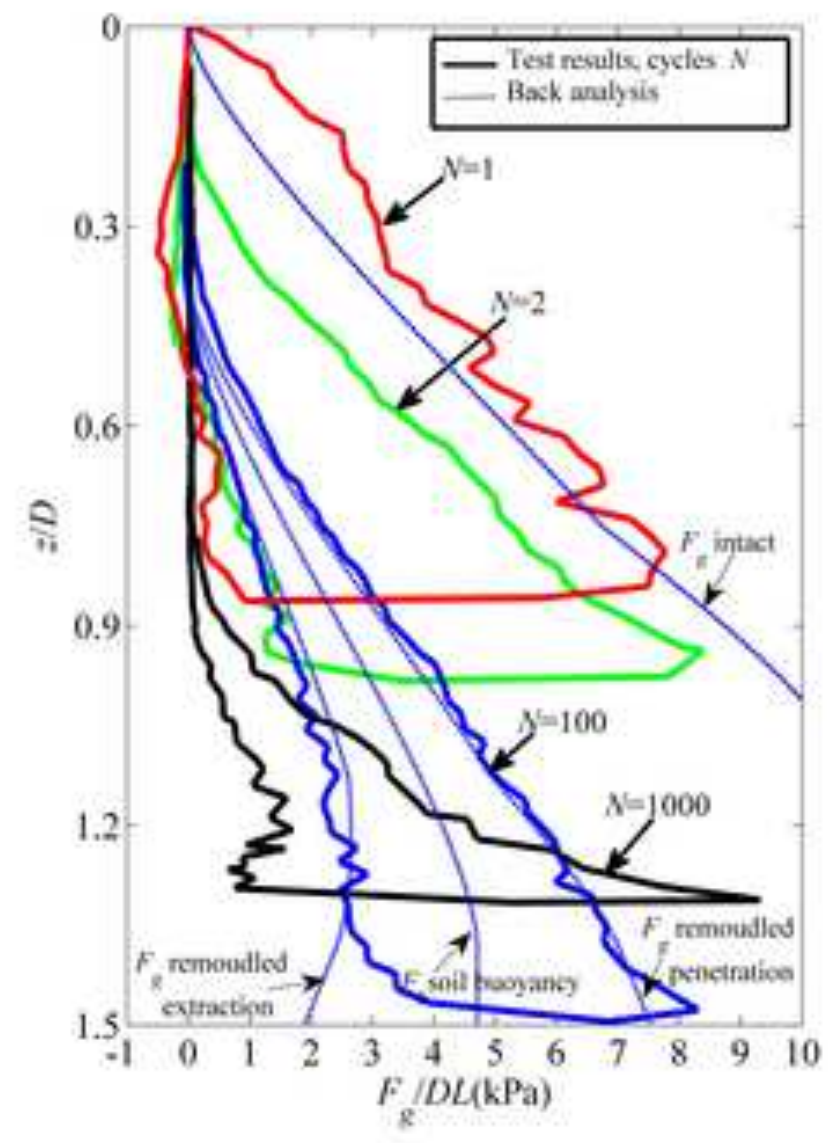




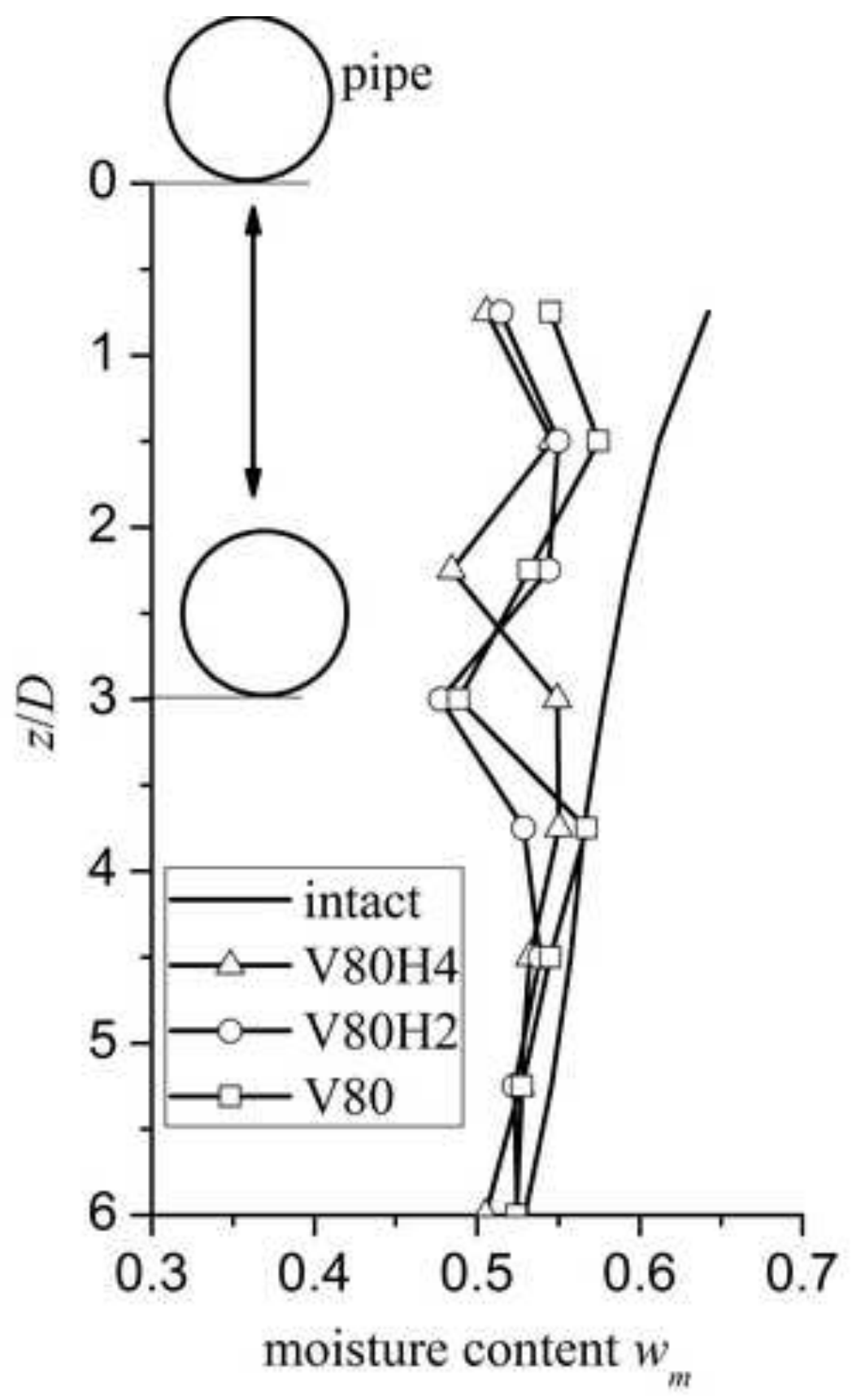




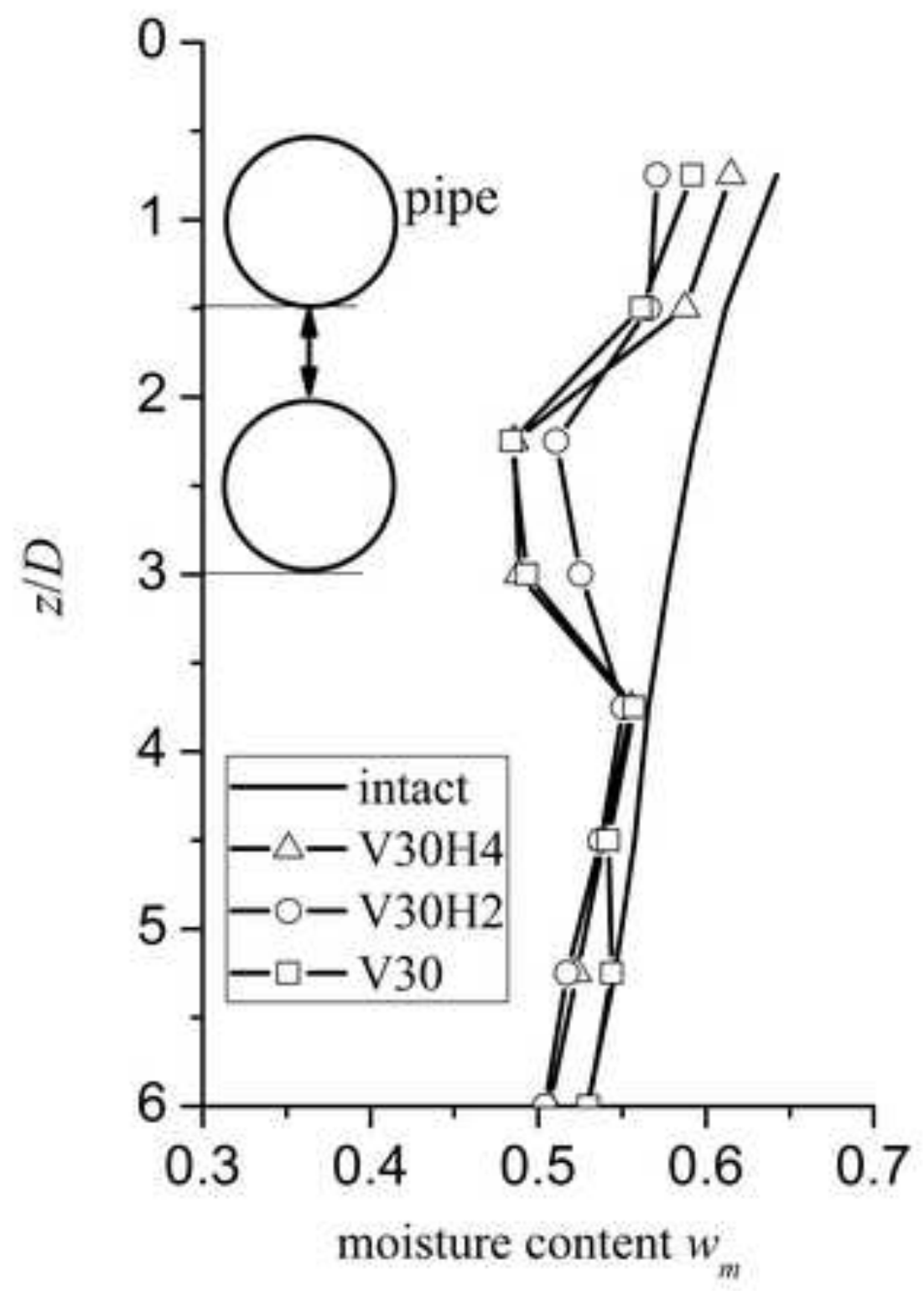




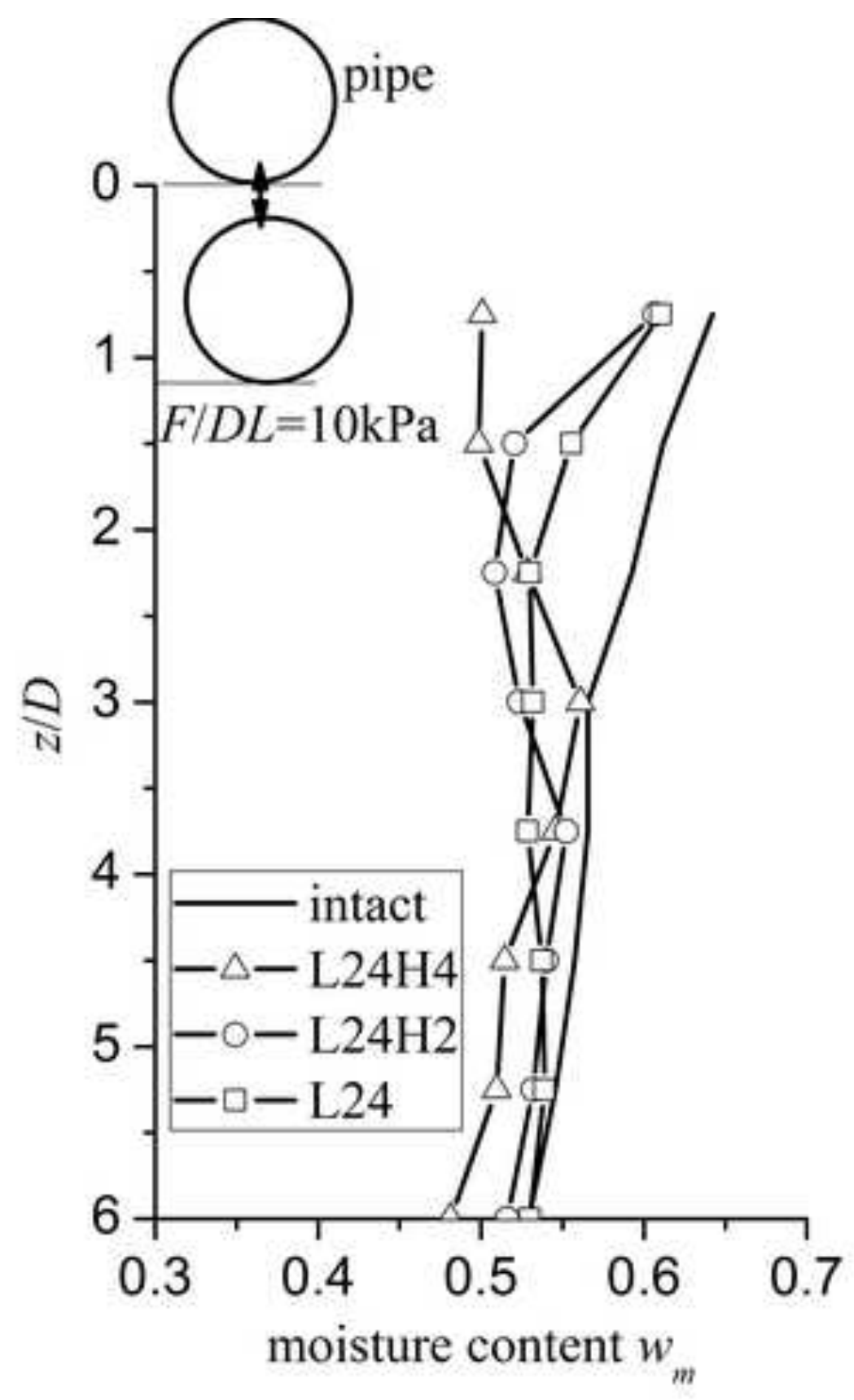




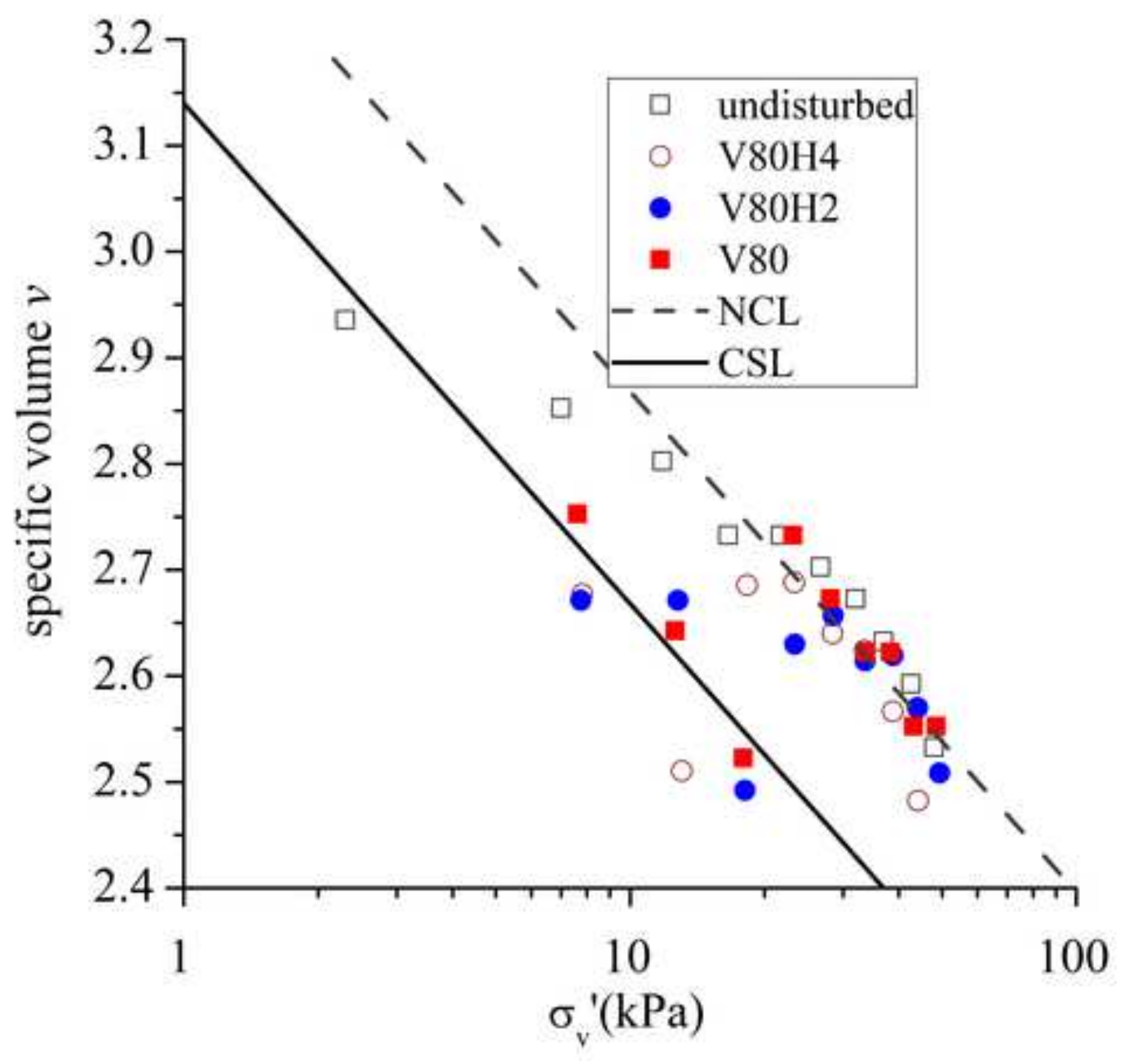




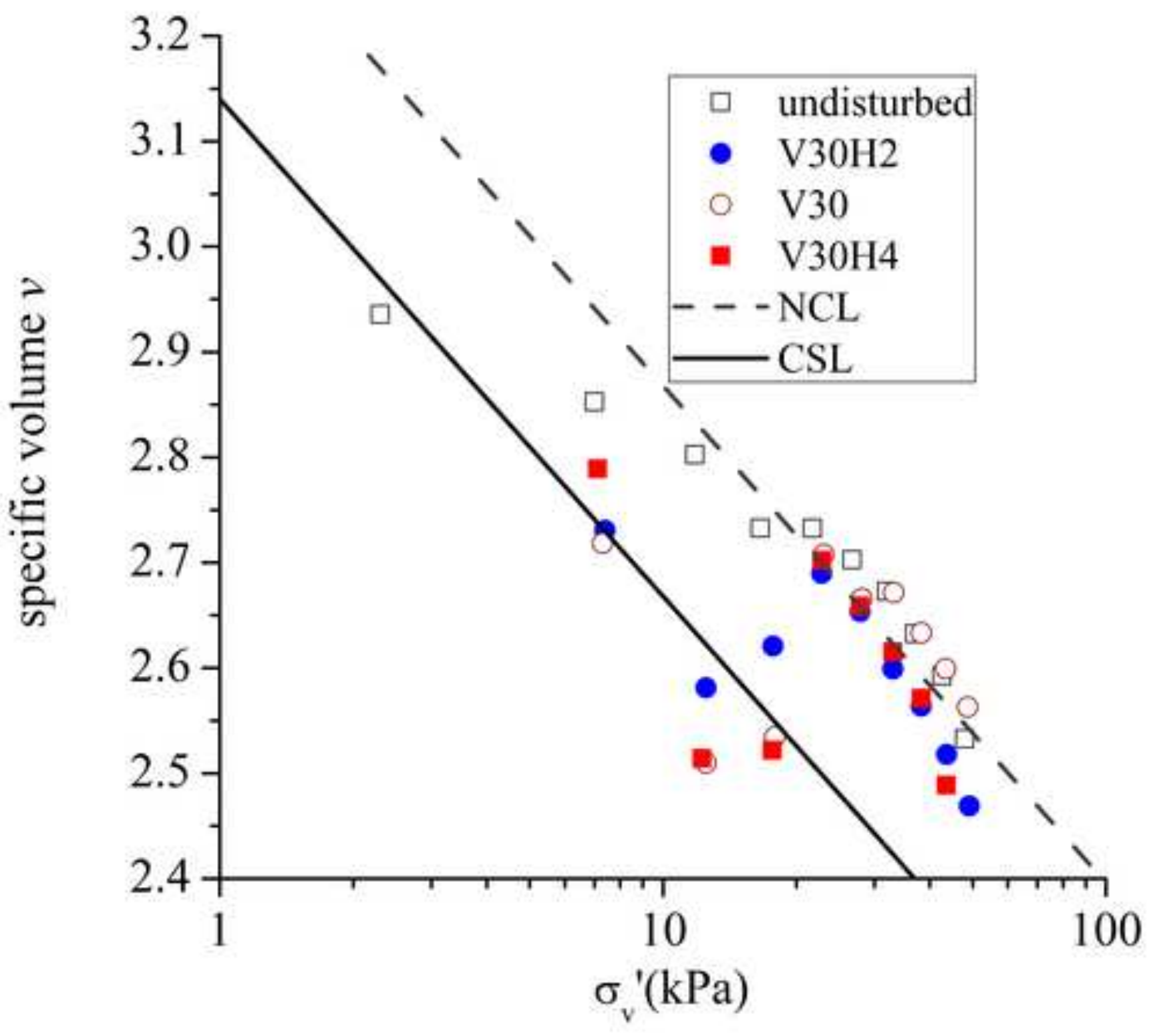




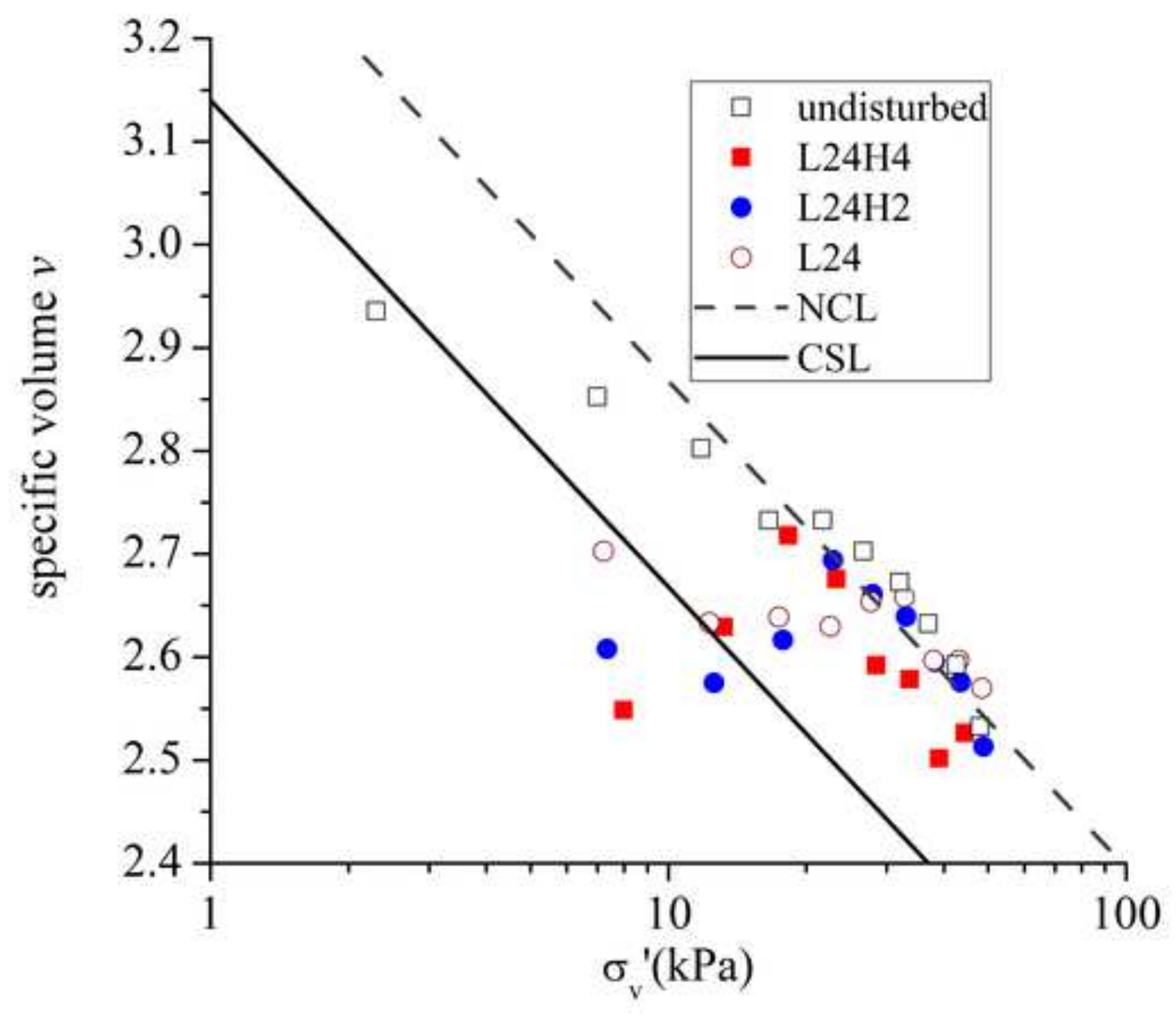




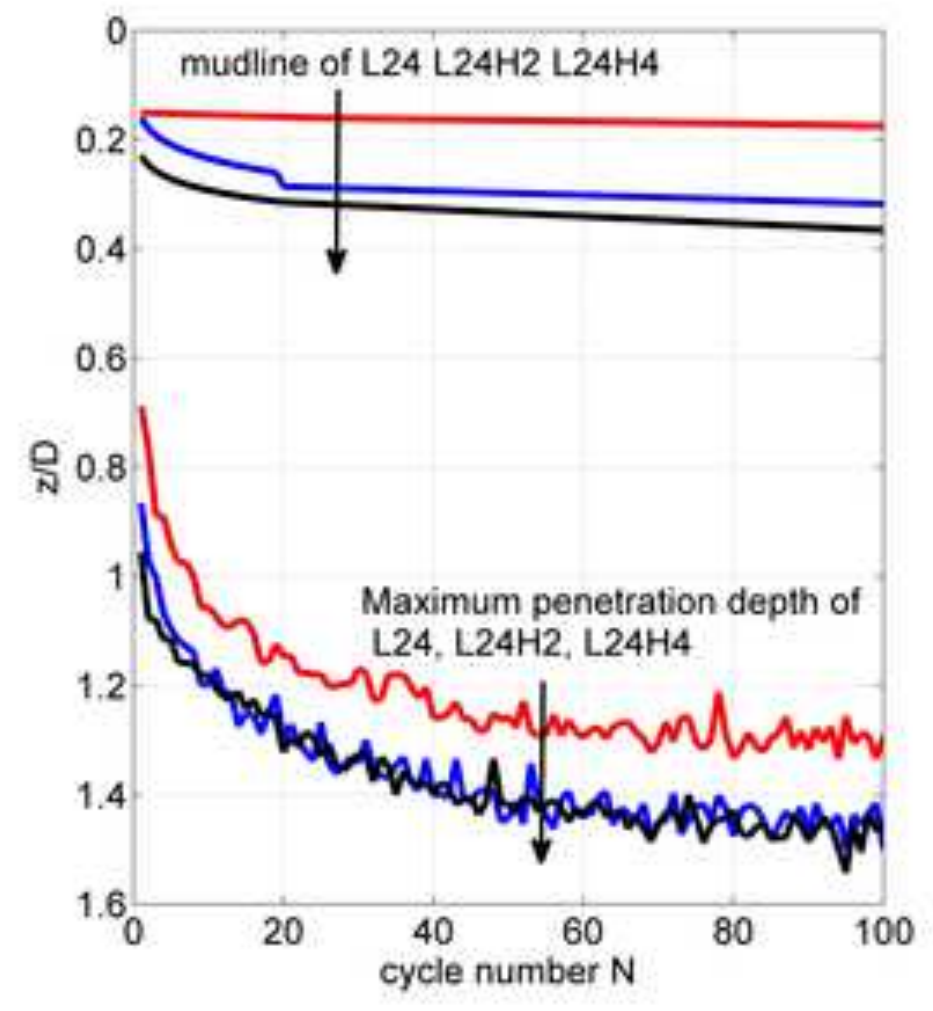




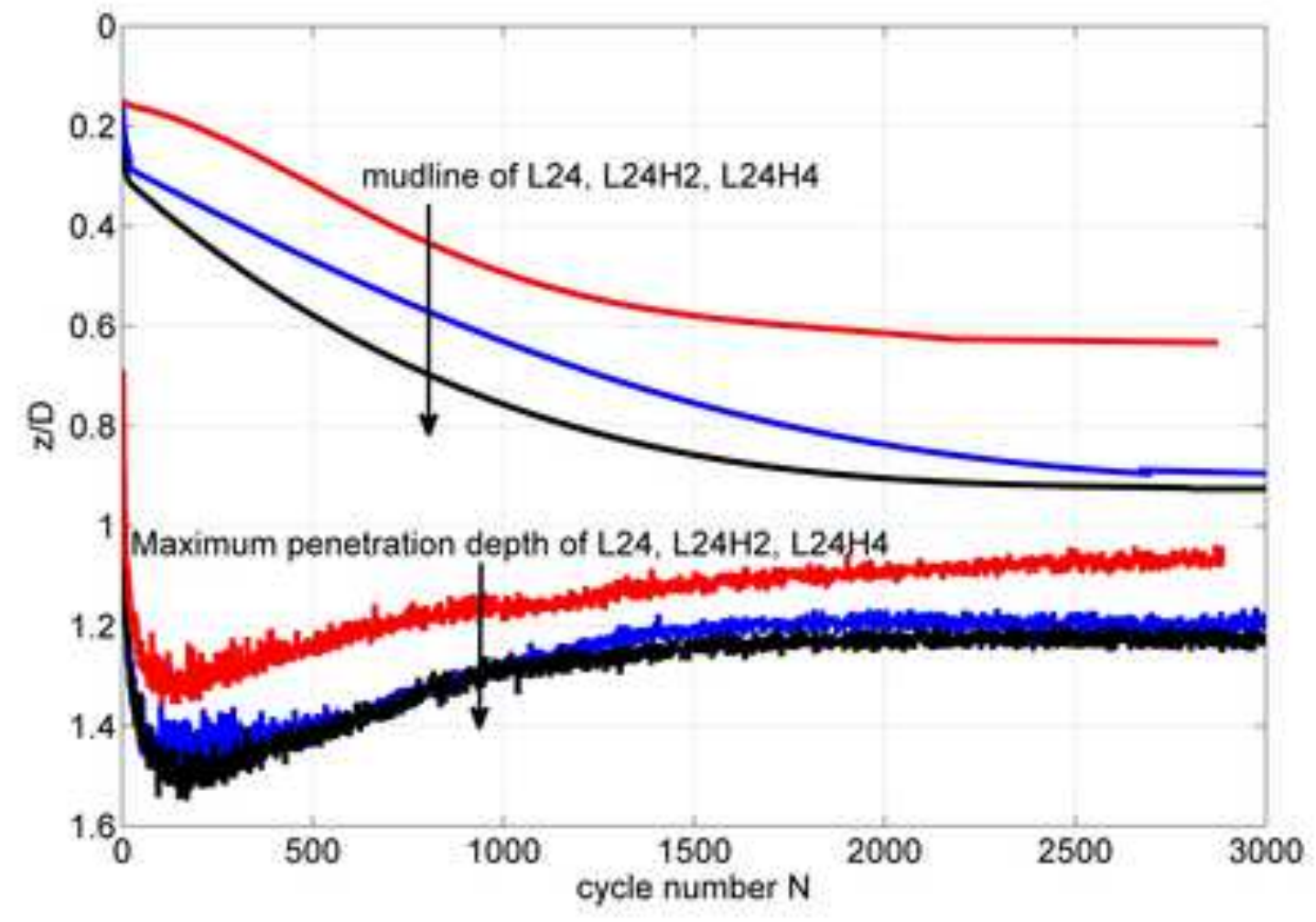




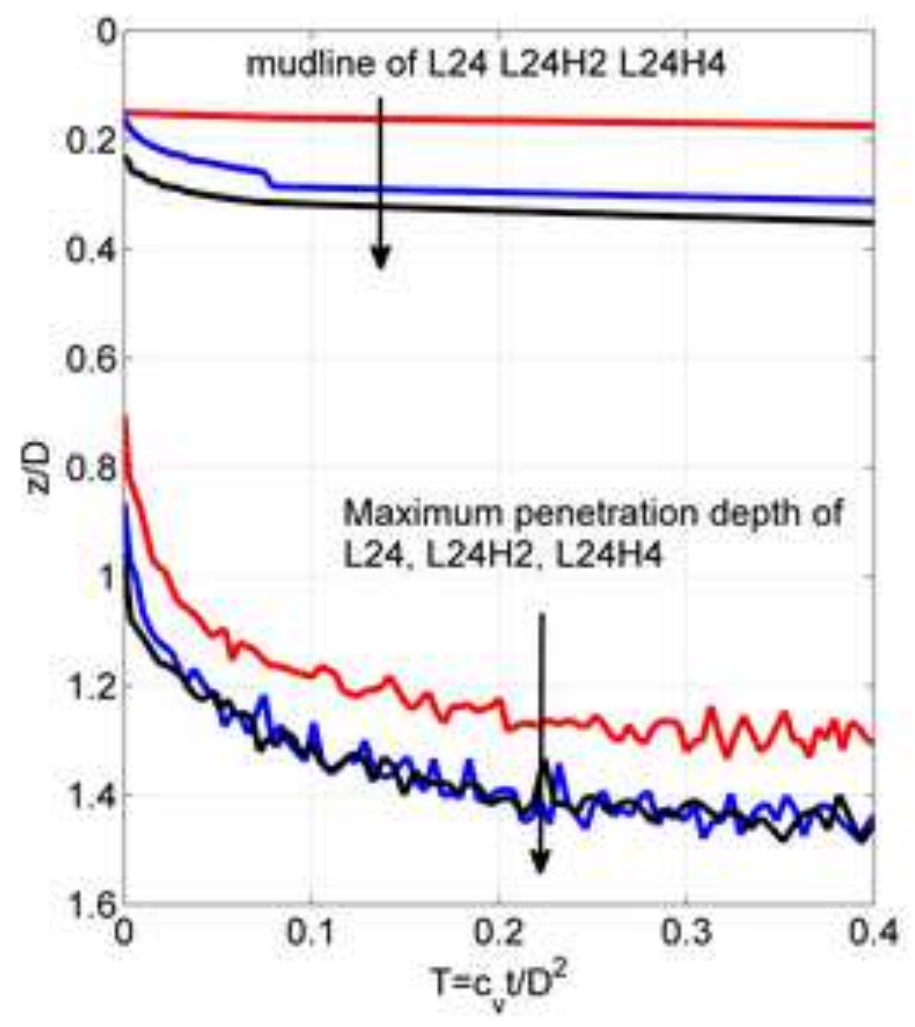




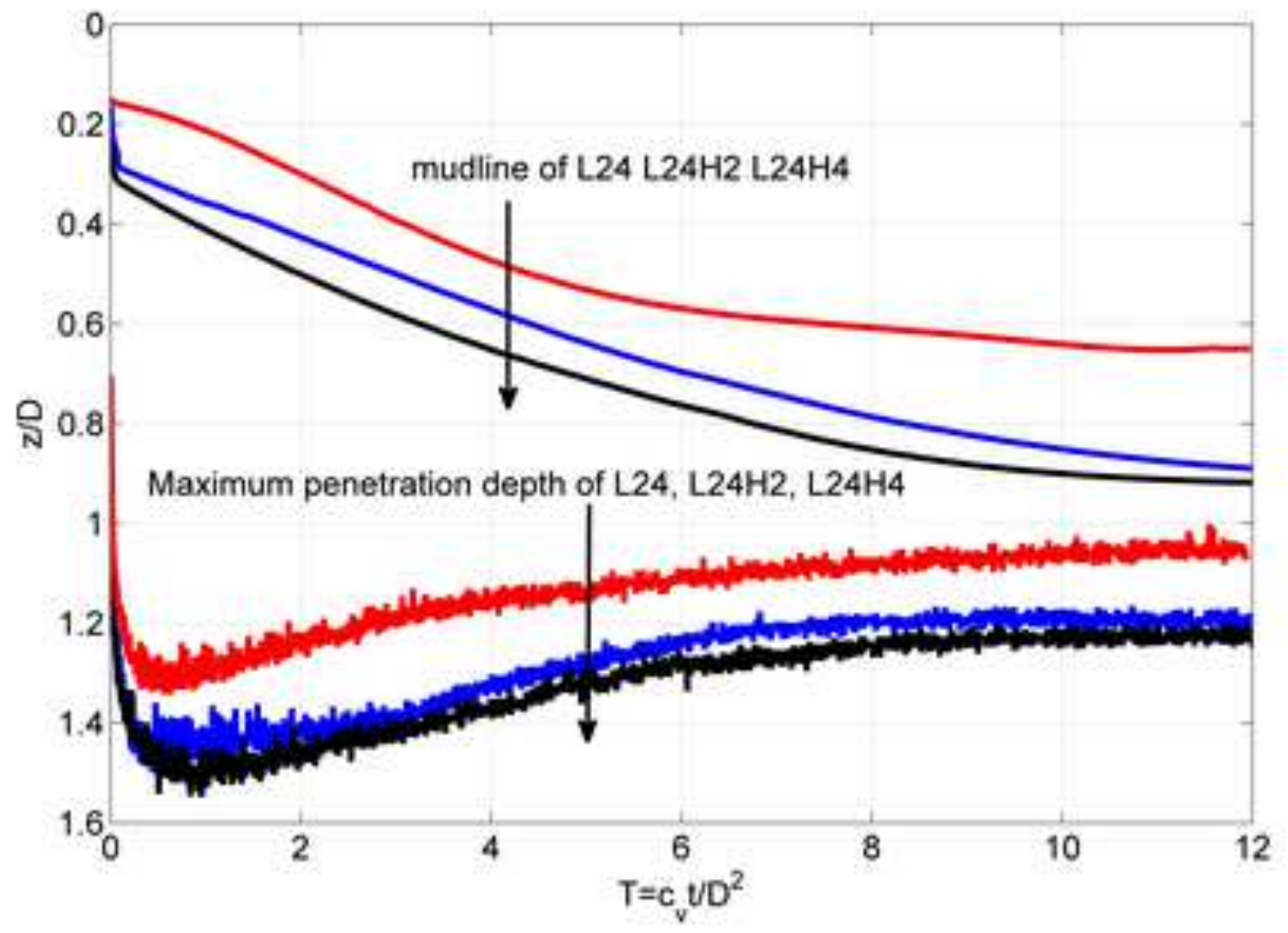




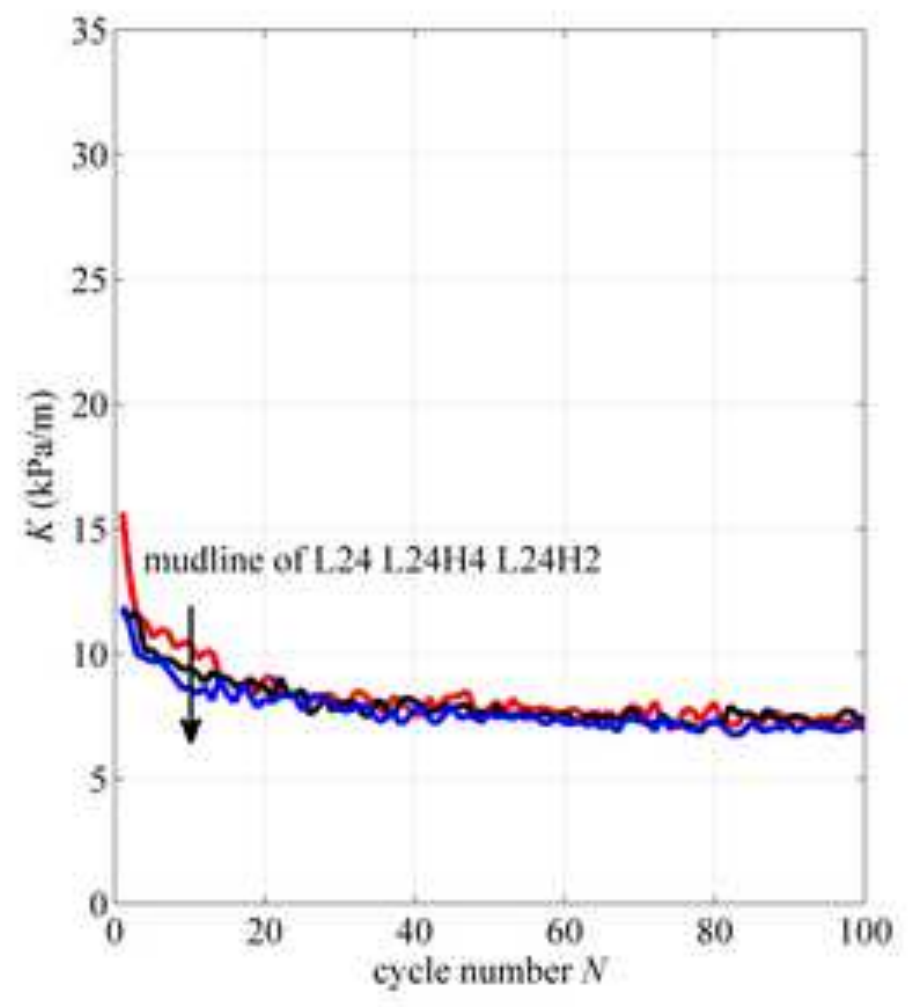




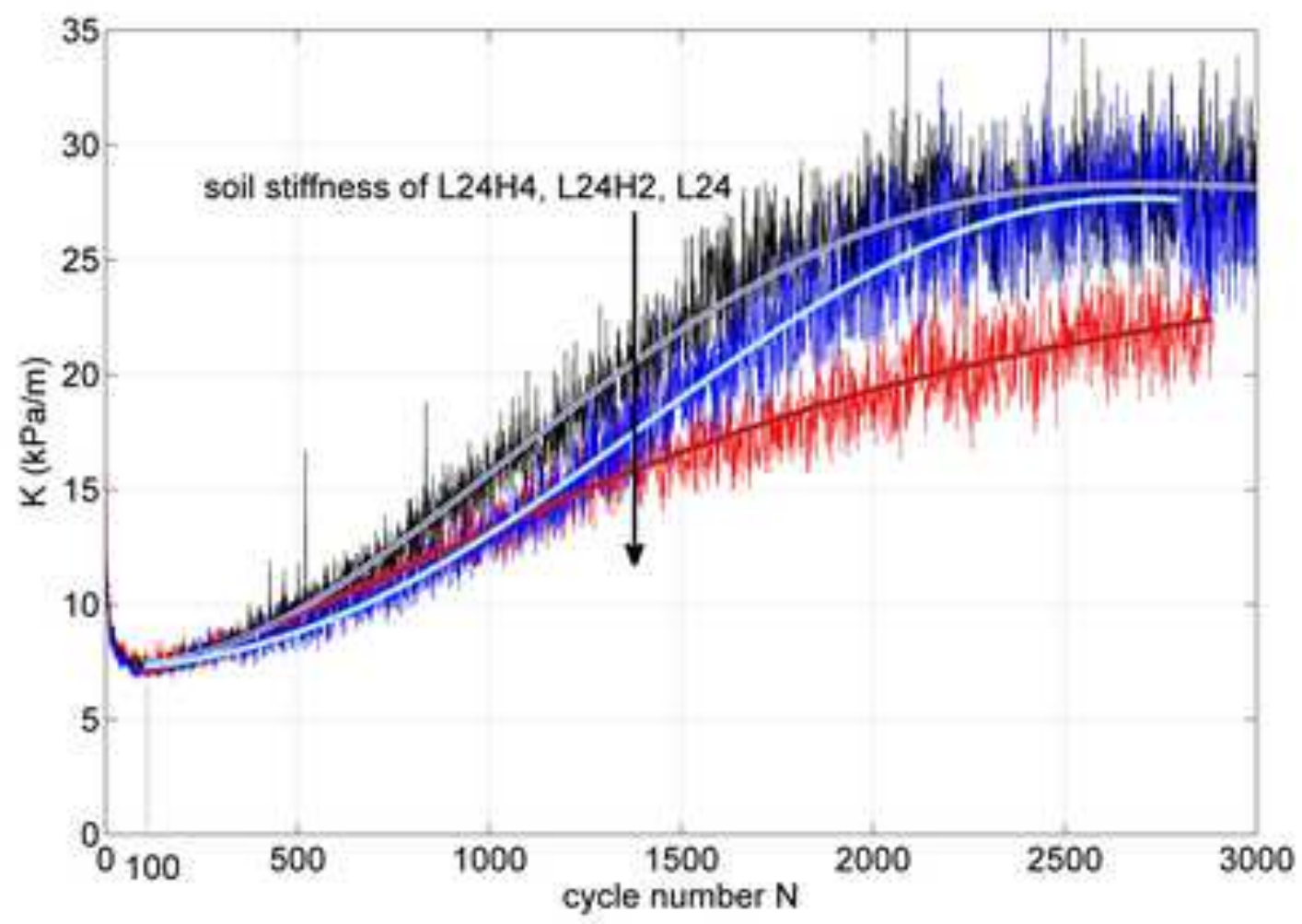




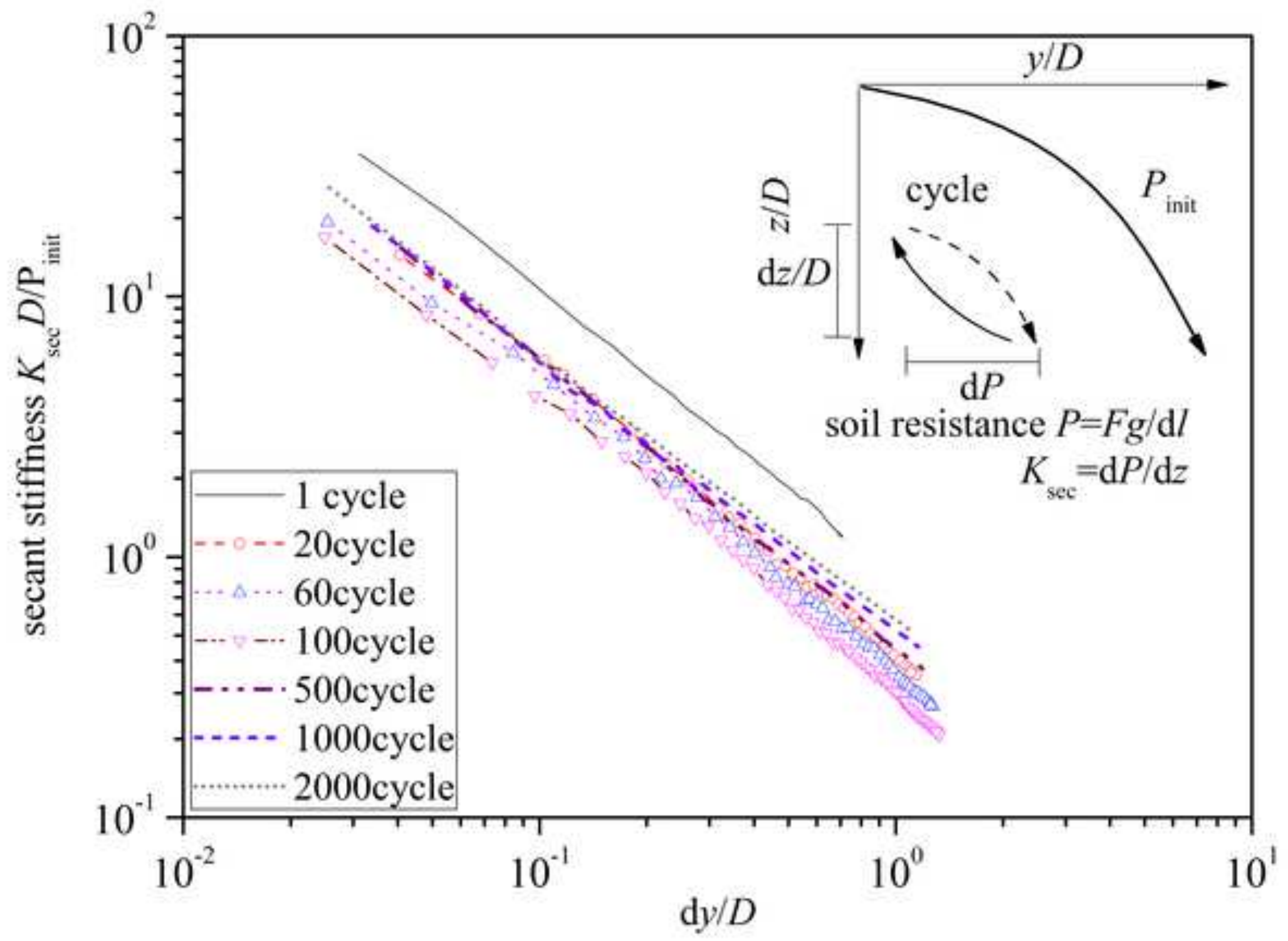

